\title{
The hydrological impact of geoengineering in the Geoengineering Model Intercomparison Project (GeoMIP)
}

\author{
Simone Tilmes, ${ }^{1}$ John Fasullo, ${ }^{1}$ Jean-Francois Lamarque, ${ }^{1}$ Daniel R. Marsh, ${ }^{1}$ \\ Michael Mills, ${ }^{1}$ Kari Alterskjær, ${ }^{2}$ Helene Muri, ${ }^{2}$ Jón E. Kristjánsson, ${ }^{2}$ Olivier Boucher, ${ }^{3}$ \\ Michael Schulz, ${ }^{3}$ Jason N. S. Cole, ${ }^{4}$ Charles L. Curry, ${ }^{5}$ Andy Jones,${ }^{6}$ Jim Haywood,,${ }^{6,7}$ \\ Peter J. Irvine, ${ }^{8}$ Duoying Ji, ${ }^{9}$ John C. Moore, ${ }^{9}$ Diana B. Karam, ${ }^{10}$ Ben Kravitz, ${ }^{11}$ \\ Philip J. Rasch, ${ }^{11}$ Balwinder Singh, ${ }^{11}$ Jin-Ho Yoon, ${ }^{11}$ Ulrike Niemeier, ${ }^{12}$ \\ Hauke Schmidt, ${ }^{12}$ Alan Robock, ${ }^{13}$ Shuting Yang, ${ }^{14}$ and Shingo Watanabe ${ }^{15}$ \\ Received 14 March 2013; revised 17 September 2013; accepted 25 September 2013; published 14 October 2013.
}

[1] The hydrological impact of enhancing Earth's albedo by solar radiation management is investigated using simulations from 12 Earth System models contributing to the Geoengineering Model Intercomparison Project (GeoMIP). We contrast an idealized experiment, G1, where the global mean radiative forcing is kept at preindustrial conditions by reducing insolation while the $\mathrm{CO}_{2}$ concentration is quadrupled to a $4 \times \mathrm{CO}_{2}$ experiment. The reduction of evapotranspiration over land with instantaneously increasing $\mathrm{CO}_{2}$ concentrations in both experiments largely contributes to an initial reduction in evaporation. A warming surface associated with the transient adjustment in $4 \times \mathrm{CO}_{2}$ generates an increase of global precipitation by around $6.9 \%$ with large zonal and regional changes in both directions, including a precipitation increase of $10 \%$ over Asia and a reduction of $7 \%$ for the North American summer monsoon. Reduced global evaporation persists in G1 with temperatures close to preindustrial conditions. Global precipitation is reduced by around $4.5 \%$, and significant reductions occur over monsoonal land regions: East Asia (6\%), South Africa (5\%), North America (7\%), and South America (6\%). The general precipitation performance in models is discussed in comparison to observations. In contrast to the $4 \times \mathrm{CO}_{2}$ experiment, where the frequency of months with heavy precipitation intensity is increased by over $50 \%$ in comparison to the control, a reduction of up to $20 \%$ is simulated in G1. These changes in precipitation in both total amount and frequency of extremes point to a considerable weakening of the hydrological cycle in a geoengineered world.

Citation: Tilmes, S., et al. (2013), The hydrological impact of geoengineering in the Geoengineering Model Intercomparison Project (GeoMIP), J. Geophys. Res. Atmos., 118, 11,036-11,058, doi:10.1002/jgrd.50868.

\section{Introduction}

[2] Geoengineering, also called climate engineering, is discussed in recent literature as a potential option for reducing the most dangerous changes to Earth's climate as

\footnotetext{
${ }^{1}$ National Center for Atmospheric Research, Boulder, Colorado, USA.

${ }^{2}$ Department of Geosciences, Meteorology and Oceanography Section, University of Oslo, Oslo, Norway.

${ }^{3}$ Laboratoire de Météorologie Dynamique, IPSL, CNRS/UPMC, Paris, France.

${ }^{4}$ Canadian Centre for Climate Modeling and Analysis, Environment Canada, Toronto, Ontario, Canada.

${ }^{5}$ School of Earth and Ocean Sciences, University of Victoria, Victoria, British Columbia, Canada.

Corresponding author: S. Tilmes, National Center for Atmospheric Research, 1850 Table Mesa Dr., 3450 Mitchell Lane, Boulder, CO 80305, USA. (tilmes@ucar.edu)

(C)2013. American Geophysical Union. All Rights Reserved. 2169-897X/13/10.1002/jgrd.50868
}

a result of large greenhouse gas increases [Launder and Thompson, 2009]. One of the proposals to "buy some time" while mitigation scenarios are aggressively ramped up, considers the reduction of incoming shortwave radiation, called Solar Radiation Management (SRM). This approach

\footnotetext{
${ }^{6}$ Met Office Hadley Centre, Exeter, UK.

${ }^{7}$ Exeter Climate Systems, University of Exeter, Exeter, UK.

${ }^{8}$ Institute for Advanced Sustainability Studies, Potsdam, Germany.

${ }^{9}$ State Key Laboratory of Earth Surface Processes and Resource Ecology, College of Global Change and Earth System Science, Beijing Normal University, Beijing, China.

${ }^{10}$ Laboratoire des Sciences du Climat et l'Environnement, CEA, CNRS, UVSQ, Gif-sur-Yvette, France.

${ }^{11}$ Pacific Northwest National Laboratory, Richland, Washington, USA.

${ }^{12}$ Max Planck Institute for Meteorology, Hamburg, Germany.

${ }^{13}$ Department of Environmental Sciences, Rutgers University, New Brunswick, New Jersey, USA.

${ }^{14}$ Danish Meteorological Institute, Copenhagen, Denmark.

${ }^{15}$ Japan Agency for Marine-Earth Science and Technology, Yokohama, Japan.
} 
is expected to offset the warming arising from increasing greenhouse gas concentrations with a corresponding reduction in solar absorption [e.g., Crutzen, 2006].

[3] Natural analogues for SRM have been observed after the occurrence of large volcanic eruptions, such as that of Mt. Pinatubo in 1991, which injected $20 \mathrm{Mt}$ of $\mathrm{SO}_{2}$ into the stratosphere [Bluth et al., 1992]. The increased planetary albedo arising from stratospheric volcanic aerosols resulted in a temporary global cooling of the Earth's surface with estimated values reaching between $0.14 \mathrm{~K}$ [Canty et al., 2013] and $0.5 \mathrm{~K}$ [Soden et al., 2002] and an ENSO adjusted tropospheric cooling of $0.4 \mathrm{~K}$ [McCormick et al., 1995]. However, ancillary effects were also observed, such as a weakening of the hydrological cycle, which was identified based on a significant reduction of the continental river discharge [Trenberth and Dai, 2007]. Further, an increase in stratospheric ozone depletion in the Arctic polar vortex was observed in 2 years following the eruption [Tilmes et al., 2008]. Simulations of a geoengineered atmosphere using sulfate aerosols also indicate changes in stratospheric dynamics and chemistry caused by SRM [Tilmes et al., 2009; Heckendorn et al., 2009].

[4] In absence of geoengineering, increasing greenhouse gas concentrations are heating the planet and warming the surface and troposphere, leading for instance to increases in atmospheric water vapor [Solomon et al., 2007]. Combined with an increased net downward radiative flux, these transient feedbacks result in a strengthening of the hydrological cycle, characterized by an increase in both total rainfall and the frequency of heavy precipitation events [Trenberth, 1999; Trenberth et al., 2003; Held and Soden, 2006; Solomon et al., 2007]. Furthermore, a robust contrast of hydrologic and radiative feedbacks between land and ocean is observed [e.g., Wang and Ding, 2006; Sutton et al., 2007] and simulated by climate models in a high $\mathrm{CO}_{2}$ environment [e.g., Joshi et al., 2008; Fasullo, 2010, 2012; Lambert et al., 2011]. Greater warming over land than over the ocean leads to contrasting feedbacks with reductions in low level relative humidity over land increasing the lifting condensation level and suppressing rainfall increases relative to those over ocean.

[5] SRM has been suggested as a mechanism to stabilize global temperatures. The continuous increase in positive forcing from increasing greenhouse gases is countered by a continuous increase in negative forcing from SRM produced by an increase in the Earth's albedo. This may be achieved by adjusting the amount of aerosol loading in the stratosphere [e.g., Wigley, 2006]. However, such experiments will alter the flow of energy throughout the climate system and reduce surface downwelling shortwave and latent heat fluxes, as studied in many different model scenarios [Govindasamy and Caldeira, 2000; Govindasamy et al., 2003; Lunt et al., 2008; Bala et al., 2008; Hegerl and Solomon, 2010; Irvine et al., 2010; Schmidt et al., 2012; Pongratz et al., 2012; Cao et al., 2012]. Some geoengineering studies have shown a significant decrease of precipitation, for example, over the Indian monsoon, as a result of geoengineering [Robock et al., 2008; Jones et al., 2010]. Kravitz and Robock [2011] and Haywood et al. [2013] have explored scenarios where injections of aerosol were made into solely one hemisphere, which results in different regional precipitation responses. However, different models and scenarios do not always agree in the sign of the change of monsoonal precipitation in response to geoengineering [Rasch et al., 2008; Jones et al., 2010]. Therefore, the impact of SRM in the context of a high $\mathrm{CO}_{2}$ environment on the global and regional precipitation across different climate models has yet to be quantified.

[6] To explore the impact of geoengineering on the climate system, the Geoengineering Model Intercomparison Project (GeoMIP) was initiated [Kravitz et al., 2011]. A set of geoengineering experiments was designed in conjunction with the fifth phase of the Coupled Model Intercomparison Project (CMIP5) effort [Taylor et al., 2012]. These geoengineering experiments were performed by a number of modeling groups. Here we use the experiment called "G1" in which the incoming solar radiation at the top of the atmosphere (TOA) is reduced to balance the radiative forcing at the TOA in an atmosphere with four times the preindustrial $\mathrm{CO}_{2}$ concentration $\left(4 \times \mathrm{CO}_{2}\right)$. This experiment thus depicts a strongly forced case of geoengineering with carbon dioxide concentrations at $1139 \mathrm{ppm}$, providing a robust signal-to-noise ratio relative to internal variability. This forcing is roughly equivalent to the Representative Concentration Pathway 8.5 radiative forcing by the end of the 21 st century.

[7] A detailed investigation of global and regional precipitation and evaporation changes in two experiments is performed: (1) an abrupt $4 \times \mathrm{CO}_{2}$ increase and (2) G1, compared to 1850 control conditions, is discussed in this paper, with a particular focus on changes over monsoonal regions. The following questions are addressed: Do climate models simulate a robust response of SRM in global and regional precipitation and how does the magnitude compare to the $4 \times \mathrm{CO}_{2}$ response? How does SRM impact precipitation intensities globally and in different regions? And finally, what is the relative compensation for $\mathrm{CO}_{2}$-induced changes and are there distinct differences evident from SRM, over land and ocean?

[8] We quantify the global and regional hydrologic changes based on GeoMIP model simulations, which are summarized in section 2 . The global temperature and precipitation response to $\mathrm{CO}_{2}$ quadrupling and SRM for individual models are discussed in section 3 . In section 4 , we investigate the question of how much global and regional precipitation patterns change with SRM in a high $\mathrm{CO}_{2}$ environment in comparison to 1850 conditions. We contrast these results to the $4 \times \mathrm{CO}_{2}$ experiment without SRM and focus on large-scale features in the tropics and northern midlatitudes. Beyond analyzing the response of total precipitation and evaporation, changes in the frequency of various precipitation intensities are also assessed, providing further insight into the changing character of rainfall. Section 5 focuses on monsoonal regions, as defined by Wang and Ding [2006], who provide an objective method for comparison of monsoon variability among observations and models. The separation of monsoonal land and ocean components helps to isolate contrasting responses based on constraints imposed by surface albedo and moisture effects. The ability of models to reproduce the area of observed monsoonal regions and precipitation amounts is evaluated in section 5.1, and the hydrologic changes in both $4 \times \mathrm{CO}_{2}$ and $\mathrm{G} 1$ relative to preindustrial conditions are investigated in section 5.2. In section 6 , we discuss results in the 
Table 1. Length of Simulations and Global Temperature Response (in K) and Solar Constant Reduction of the 12 GeoMIP Models, Summarized in Kravitz et al. [2013] ${ }^{\mathrm{a}}$

\begin{tabular}{lcccccc}
\hline Model $^{\mathrm{b}}$ & $\begin{array}{c}4 \times \mathrm{CO}_{2} \\
\text { (years) }\end{array}$ & $\begin{array}{c}\mathrm{G} 1 \\
\text { (years) }\end{array}$ & $\begin{array}{c}4 \times \mathrm{CO}_{2} \\
\text { Minus } 1850\end{array}$ & $\begin{array}{c}\mathrm{G} 1 \\
\text { Minus } 4 \times \mathrm{CO}_{2}\end{array}$ & $\begin{array}{c}\mathrm{G} 1 \\
\text { Minus 1850 }\end{array}$ & Solar Reduction \\
\hline BNU-ESM & $1 \times 150$ & $1 \times 50$ & $5.71(6.14)$ & -5.08 & 0.59 & $3.8 \%$ \\
CanESM2 & $1 \times 150$ & $3 \times 50$ & $5.42(5.88)$ & -5.41 & 0.01 & $4.0 \%$ \\
CESM-CAM5.1 & $1 \times 150$ & $1 \times 50$ & $4.93(5.28)$ & -5.09 & -0.16 & $4.7 \%$ \\
CCSM4 & $2 \times 150$ & $3 \times 50$ & $4.48(4.82)$ & -4.26 & 0.22 & $4.1 \%$ \\
EC-EARTH DMI & $1 \times 100$ & $1 \times 100$ & 4.78 & -4.76 & 0.02 & $4.3 \%$ \\
GISS-E2-R & $3 \times 70$ & $3 \times 70$ & 2.87 & -3.16 & -0.29 & $4.5 \%$ \\
HadGEM2-ES & $1 \times 150$ & $1 \times 49$ & $5.64(6.20)$ & -5.51 & 0.12 & $3.9 \%$ \\
HadCM3 & $1 \times 149$ & $1 \times 50$ & $5.11(5.59)$ & -5.04 & 0.07 & $4.1 \%$ \\
IPSL-CM5A-LR & $1 \times 260$ & $1 \times 50$ & $5.59(5.76)$ & -5.50 & 0.10 & $3.5 \%$ \\
MIROC-ESM & $1 \times 150$ & $1 \times 52$ & $5.91(6.42)$ & -6.13 & -0.22 & $5.0 \%$ \\
MPI-ESM-LR & $1 \times 150$ & $1 \times 50$ & $5.36(5.87)$ & -5.40 & -0.04 & $4.7 \%$ \\
NorESM1-M & $1 \times 150$ & $1 \times 50$ & $3.76(4.14)$ & -3.79 & -0.02 & $4.0 \%$ \\
\hline
\end{tabular}

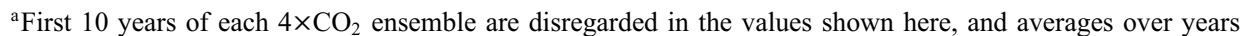
$101-150$ are shown in brackets (fourth column).

${ }^{b}$ BNU-ESM, Beijing Normal University-Earth System Model; CanESM2, The Second Generation Canadian Earth System Model; CESM-CAM5.1, The Community Climate System Model Version 5.1; CCSM4, The Community Climate System Model Version 4; EC-EARTH DMI, European Earth System Model based on ECMWF Models (Seasonal Forecast System), Danish Meteorological Institute; GISS-E2-R, Goddard Institute for Space Studies ModelE version 2; HadCM3, Hadley Centre coupled model 3; IPSL-CM5A-LR, Institut Pierre Simon Laplace ESM; MIROC-ESM, Model for Interdisciplinary Research on Climate-Earth System Model; MPI-ESM-LR, Max Planck Institute ESM; NorESM1-M, Norwegian ESM.

context of the hydrological cycle and a summary is given in section 7.

\section{Model Experiments and Analysis}

[9] Results from 12 climate models that performed three model experiments are used: a preindustrial control (labeled 1850 ), an abrupt quadrupling of $\mathrm{CO}_{2}$ (labeled $4 \times \mathrm{CO}_{2}$ ), and the G1 GeoMIP experiment that adds SRM to the $4 \times \mathrm{CO}_{2}$ scenario. A detailed description of the setup of the GeoMIP experiments is outlined in Kravitz et al. [2011]. For each experiment, up to three ensemble members are available per model. The 1850 control simulations are derived from an extended integration designed to produce equilibrated global mean surface temperatures. At least 50 years of this well-balanced experiment are available for all models.

[10] The $4 \times \mathrm{CO}_{2}$ experiment (also called "abrupt $4 \times \mathrm{CO}_{2}$ ") is started from the 1850 control experiment, and the simulation extended for 150 years for most models (two models provided only $3 \times 70$ and 100 year simulations) (Table 1 , second column). For this experiment, a strong radiative imbalance exists for at least 10 years at the TOA caused by a $\mathrm{CO}_{2}$ forcing of about 6 to $9 \mathrm{Wm}^{-2}$, derived using the regression method described by Gregory et al. [2004] (not shown). For this reason, precipitation and temperature changes from the first 10 years of this experiment are not considered. All subsequent years of the $4 \times \mathrm{CO}_{2}$ experiment are included in our analysis in order to maximize the number of years per simulation for all the models, including those with shorter simulations. Considering all years of each ensemble besides the first 10 years to calculate the temperature and precipitation response results in smaller changes in temperature and precipitation than if considering years 101-150 only, as done in Schmidt et al. [2012]. This is because $4 \times \mathrm{CO}_{2}$ simulations still experience moderate transient adjustment after the first decade [Kravitz et al., 2013]. Average temperature changes are $\approx 0.5 \mathrm{~K}$ smaller, and precipitation changes are $\approx 1 \%$ smaller if averaging over the longer period (see Table 1, fourth column, and Table 3, third column, on the left), in agreement with results presented in Table 4 by Schmidt et al. [2012].

[11] The G1 experiment is branched off the 1850 control experiment. The climate in this experiment is controlled by two forcings, an instantaneous quadrupling of $\mathrm{CO}_{2}$ and a corresponding reduction of incoming solar radiation in reducing the solar constant to balance the residual TOA imbalance. The experiment is performed for at least 50 years with one to three ensemble simulations [Kravitz et al., 2013]. We include all available years of the G1 simulation in our analysis (Table 1, third column), following the approach of Schmidt et al. [2012]. Since temperature changes are very small in G1, we assume 50 years to be sufficient to represent steady state conditions. The simulation is designed to portray a strongly forced climate system, to produce a large signal-to-noise ratio in the context of internal variability in response to solar dimming. These results are expected to differ to some degree from transient geoengineering experiments, which are characterized by a steady ramp-up of greenhouse gas concentrations and solar dimming. However, many of the principal processes are expected to be similar between the two simulations, as further discussed below.

[12] General features of the climate response in the G1 experiment are described by Kravitz et al. [2013] and by Schmidt et al. [2012] who considered only a subset of the models. For the G1 simulation, the incoming shortwave radiation was reduced by an amount that differed a bit between individual model, ranging from $3.8 \%$ to $5.0 \%$ (Table 1 , last column). This value differs across models due to their individual responses to solar dimming, for instance, due to differences in cloud feedbacks [Schmidt et al., 2012]. Most models were able to achieve a global balance. However, as described by Schmidt et al. [2012] and Kravitz et al. [2013], spatial and temporal structure in net radiative forcing at TOA $\left(\mathrm{F}_{\mathrm{TOA}}\right)$ persists due to differences in spatiotemporal patterns 
Table 2. Convection Schemes of Different GeoMIP Models

\begin{tabular}{|c|c|}
\hline Model & Convection Scheme \\
\hline BNU-ESM & based on Zhang and McFarlane [1995] convection scheme [Zhang and Mu, 2005] \\
\hline CanESM2 & $\begin{array}{l}\text { separated deep moist (bulk mass flux) scheme and shallow moist convection scheme } \\
\text { [von Salzen et al., 2013] }\end{array}$ \\
\hline CESM-CAM5.1-FV & $\begin{array}{c}\text { same deep convection scheme as in CCSM4, but with updated shallow convection } \\
\text { scheme [Park and Bretherton, 2009] }\end{array}$ \\
\hline CCSM4 & $\begin{array}{l}\text { deep convection is treated by the Zhang and McFarlane [1995] scheme, with } \\
\text { improvements due to Richter and Rasch [2008] and Neale et al. [2008] }\end{array}$ \\
\hline EC-EARTH DMI & $\begin{array}{l}\text { bulk mass-flux scheme for deep shallow and midlevel convection [Tiedtke, 1989] with } \\
\text { updates (http://www.ecmwf.int/research/ifsdocs/CY33r1/PHYSICS/IFSPart4.pdf) }\end{array}$ \\
\hline GISS-E2-R & $\begin{array}{l}\text { mass-flux approach to cumulus parameterization with one undiluted and one entraining } \\
\text { plume, similar to Del Genio and Yao [1993] }\end{array}$ \\
\hline HadGEM2-ES & $\begin{array}{l}\text { mass-flux convection scheme with representation of cloud ensemble characteristics } \\
\text { and stability-dependent closure [Gregory and Rowntree, 1990]. }\end{array}$ \\
\hline HadCM3 & $\begin{array}{l}\text { mass-flux convection scheme with representation of cloud ensemble characteristics } \\
\text { and stability-dependent closure [Gregory and Rowntree, 1990] }\end{array}$ \\
\hline IPSL-CM5A-LR & $\begin{array}{l}\text { deep convection scheme using the episodic mixing and buoyancy sorting Emanuel } \\
\text { scheme [Emanuel, 1991]. }\end{array}$ \\
\hline MIROC-ESM & modified version of the Arakawa and Schubert [1974] scheme [Emori et al., 2001] \\
\hline MPI-ESM-LR & $\begin{array}{l}\text { bulk mass-flux scheme for deep shallow and midlevel convection [Tiedtke, 1989] } \\
\text { with modifications for penetrative convection according to Nordeng [1994]. }\end{array}$ \\
\hline NorESM1-M & $\begin{array}{l}\text { deep convection is treated by the Zhang and McFarlane [1995] scheme, with } \\
\text { improvements due to Richter and Rasch [2008] and Neale et al. [2008] }\end{array}$ \\
\hline
\end{tabular}

of the two opposing forcings, resulting in a net decrease of the $\mathrm{F}_{\mathrm{TOA}}$ at low latitudes and a net increase in high latitudes. Consequently, a cooling in comparison to 1850 conditions was found in the tropics, while the high latitudes warm strongly with a maximum in winter for each hemisphere. Precipitation changes were briefly investigated in these studies, considering the change of global mean precipitation, changes in the Bowen ratio [Schmidt et al., 2012], and the difference between precipitation and evaporation [Kravitz et al., 2013]. Based on results from only four models, Schmidt et al. [2012] identified a consistent decrease of precipitation in South-East Asia for all the models, while models do not agree in sign for the other monsoonal regions. Kravitz et al. [2013] found a reduction in precipitation minus evaporation $(P-E)$ by up to $1.4 \mathrm{~mm} \mathrm{day}^{-1}$ in some tropical regions but less than $0.2 \mathrm{~mm}$ day $^{-1}$ in summer over monsoonal regions for the ensemble mean.

[13] In our analysis, we contrast precipitation and evaporation changes of two perturbed experiments, the $4 \times \mathrm{CO}_{2}$ and the G1 experiments, in comparison to 1850 control conditions. Monthly outputs for near-surface temperature, total precipitation, and evaporation are used from available ensemble members provided by each model group. Areaweighted global and regional responses are derived. Other variables such as runoff and soil moisture that are part of the hydrological cycle vary greatly between models, and there are uncertainties in observations of the fields, so we choose not focus on them in this study (see section 6 for further discussion).

[14] Specifics of each model, including their vertical and horizontal resolution, are summarized by Kravitz et al. [2013, Table 1]. Model parameterizations of convection and microphysics are listed in Table 2.

\section{Global Temperature and Precipitation Response}

[15] The simulated global surface air temperature response in the $4 \times \mathrm{CO}_{2}$ experiment compared to the 1850 control experiment varies in proportion to model sensitivity [Gregory et al., 2004]. The global average temperature change ranges between $2.9 \mathrm{~K}$ and $5.9 \mathrm{~K}$ for different models, ignoring the first 10 years of the simulation (Figure 1, top panel, and Table 1, fourth column). Changes in global precipitation between the $4 \times \mathrm{CO}_{2}$ and the control experiment are positively correlated to warming and, therefore, to climate sensitivity. The increase of global precipitation derived from different models ranges between 0.13 and 0.30 $\mathrm{mm}$ day $^{-1}(4.5-12 \%)$ with the GISS model being an outlier showing an increase of only about $0.07 \mathrm{~mm}^{-1 a y^{-1}}$ or $2 \%$.

[16] The initial decrease of precipitation due to the instant quadrupling of $\mathrm{CO}_{2}$ in the first few months of the simulation is called the "fast response" or "rapid adjustment" [e.g., Andrews et al., 2009; Andrews and Forster, 2010; Bala et al., 2010], and is followed by the transient feedback, usually called the "slow response." The fast response is believed to be caused by the initial increase of atmospheric stability in a high $\mathrm{CO}_{2}$ environment. The transient feedback is driven by changes in surface temperature, which is a function of the uptake of heat by the ocean in a warming climate and its impact on water vapor and the divergent tropical circulation [e.g., Held and Soden, 2006]. Precipitation changes in models are often reported in changes per Kelvin, considering the slow response only.

[17] The transient feedback is estimated here by fitting a straight line through the annual averaged global precipitation changes regressed against temperature changes for the first 10 years of the $4 \times \mathrm{CO}_{2}$ experiment starting from 1850 average conditions (Figure 1, thin colored line). Intersections of each line with the $x$ axis can be understood as the fast response of the precipitation for each model for the $4 \times \mathrm{CO}_{2}$ experiment [see Andrews et al., 2009].

[18] The estimated range of the transient feedback is 0.06$0.10 \mathrm{~mm} \mathrm{day}^{-1} \mathrm{~K}^{-1}\left(2.0-3.5 \% \mathrm{~K}^{-1}\right)$. GeoMIP and therefore CMIP5 results are in good agreement with earlier studies using the CMIP3 archive (Held and Soden [2006], 2.2\% K $\mathrm{K}^{-1}$, Andrews and Forster [2010], 2.4\% $\mathrm{K}^{-1}$ ). The transient feedback will not be further discussed, since it does not include 

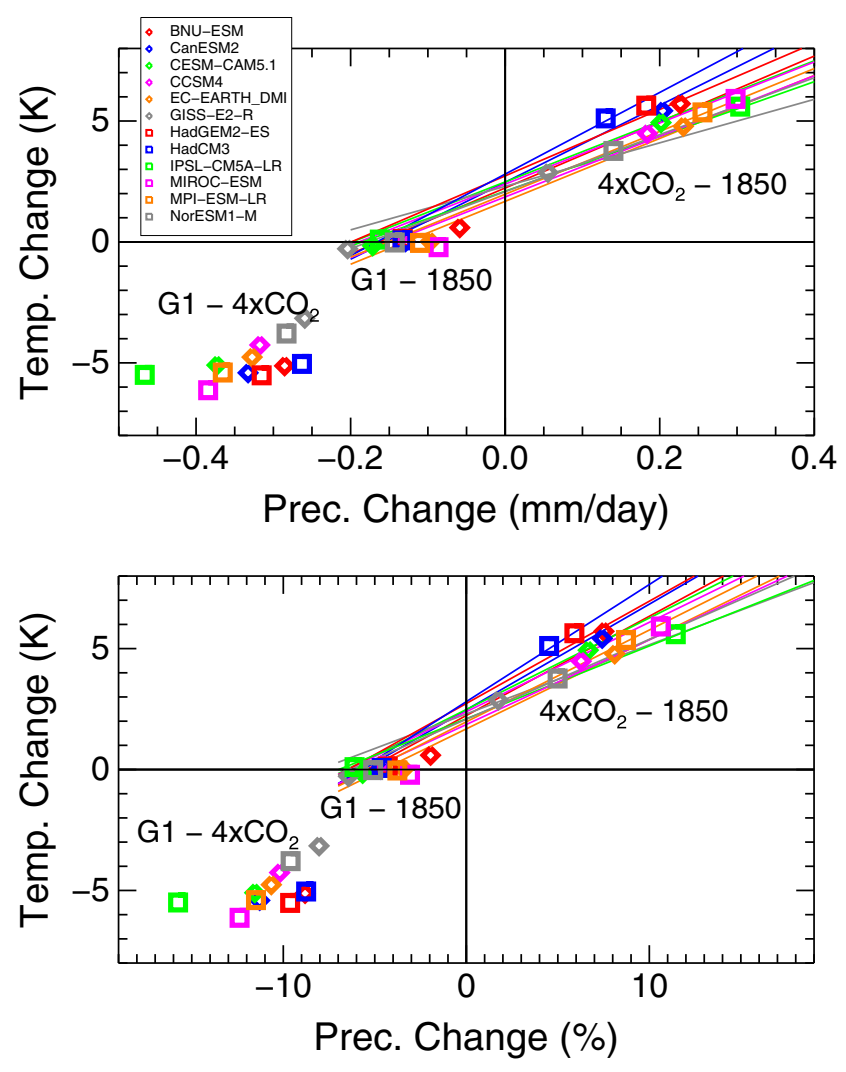

Figure 1. Annual and global averages of (top) absolute and (bottom) relative precipitation response to change in temperature for three cases: $4 \times \mathrm{CO}_{2}-1850, \mathrm{G} 1-4 \times \mathrm{CO}_{2}$, and $\mathrm{G} 1-$ 1850. All symbols are averages over all available ensemble members for each model and all years, besides the first 10 years for the $4 \times \mathrm{CO}_{2}$ experiment, see text and Table 1. For each model, a linear fit (colored line) is derived from annual and global precipitation changes versus temperature changes between $4 \times \mathrm{CO}_{2}$ experiment and 1850 conditions using the first 10 years of each simulation.

the transient adjustment of the fast response, and therefore results in an overestimation of the precipitation response to $\mathrm{a} \mathrm{CO}_{2}$ increase [Andrews and Forster, 2010].

[19] Contrasting G1 and $4 \times \mathrm{CO}_{2}$ simulations highlights the precipitation response to solar dimming in a high $\mathrm{CO}_{2}$ environment (Figure 1, lower left quadrant of each panel). Global mean temperatures in the G1 experiment are 3.2$6.1 \mathrm{~K}$ cooler compared to the $4 \times \mathrm{CO}_{2}$ experiment (Figure 1, top panel; Table 1, fifth column), and precipitation rates are reduced by 0.26 to $0.38 \mathrm{~mm}$ day $^{-1}(8-12.5 \%)$ for most models, with the largest reduction of $0.47 \mathrm{~mm}_{\text {day }}{ }^{-1}$ $(16 \%)$ in IPSL-CM5A-LR. Precipitation changes due to decreases in solar forcing are largely governed by the slow response referred to above [Andrews and Forster, 2010]. These changes are very similar, but have opposite sign compared to the slow response under the transient adjustment of the $4 \times \mathrm{CO}_{2}$ experiment, as they relate to changes in the surface energy balance. Global mean precipitation differences between $\mathrm{G} 1$ and $4 \times \mathrm{CO}_{2}$ are also positively correlated to the surface temperature change (correlation coefficient $r=0.80$ ).
[20] On the other hand, considering the G1 experiment with regard to 1850 conditions, global mean surface temperatures do not change significantly (Figure 1, middle cluster). Global precipitation decreases by $0.13 \pm 0.04 \mathrm{~mm}^{\text {day }}{ }^{-1}$ $(4.5 \pm 1.3 \%)$ (see Figure 1). Global average precipitation deviations from the control are thus more than half of the precipitation changes induced by a quadrupling of $\mathrm{CO}_{2}$. Total precipitation amount is controlled by the surface energy budget [Hansen et al., 1997], and the slow response in the precipitation rate is expected to be small. All the models simulate a global near-surface temperature change within $\pm 0.3 \mathrm{~K}$ compared to the control, whereas the BNU-ESM model is biased high by $0.59 \mathrm{~K}$ (Table 1, column 6). Interestingly, the precipitation reduction in G1 is correlated to the fast response of the $4 \times \mathrm{CO}_{2}$ experiment ( $r=0.88$, if ignoring the BNU-ESM model) with a slightly smaller reduction in precipitation than suggested by the fast response (Figure 2). Therefore, models with the largest fast response of the $4 \times \mathrm{CO}_{2}$ experiment also produce the greatest reductions in precipitation in response to solar dimming.

[21] This suggests that both the fast response in the $4 \times \mathrm{CO}_{2}$ experiment and the hydrologic sensitivity under G1 forcing may underlay a similar mechanism. An initial increase in atmospheric stability in the G1 experiment is shown by Kravitz et al. [2013] and is also simulated for other geoengineering experiments [e.g., Bala et al., 2008]. However, recent studies [Cao et al., 2012; Fyfe et al., 2013] have suggested that the reduction in evapotranspiration from plants over land [e.g., Doutriaux-Boucher et al., 2009; Cao et al., 2010] plays an important role as well. In Appendix A, we explore this issue using the National Center for Atmospheric Research CCSM4 in contrasting results of the first year of the model experiments performed with and without an interactive land carbon cycle. We show that the abrupt $\mathrm{CO}_{2}$ increase reduces the stomatal conductance and results in a similar initial change of surface fluxes in both the $4 \times \mathrm{CO}_{2}$ and $\mathrm{G} 1$ experiments. For the first year of the

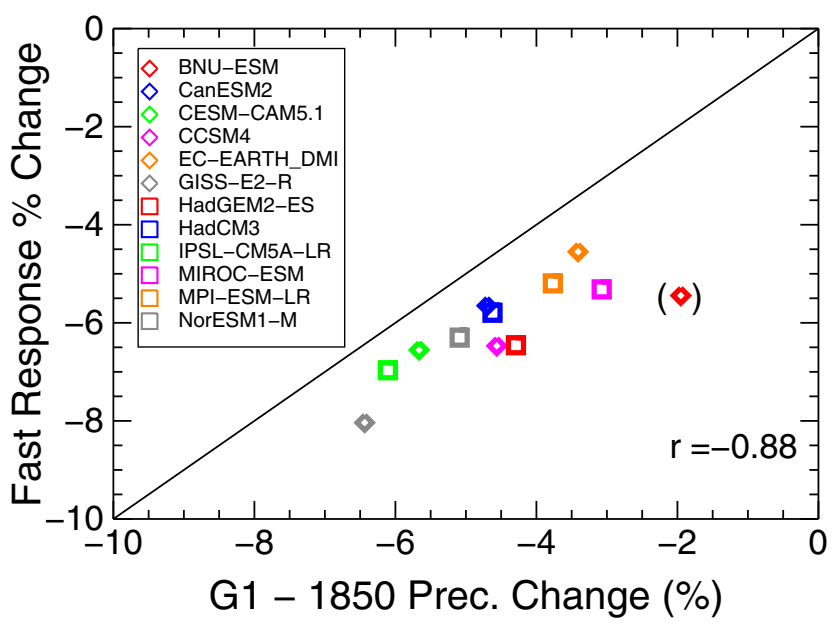

Figure 2. Fast precipitation response (see text) in relative terms derived from Figure 1 (bottom panel) versus precipitation change for G1-1850 for different models (colored symbols). The correlation of these values (lower right corner) is derived while ignoring the BNU-ESM model (see text for further details). 


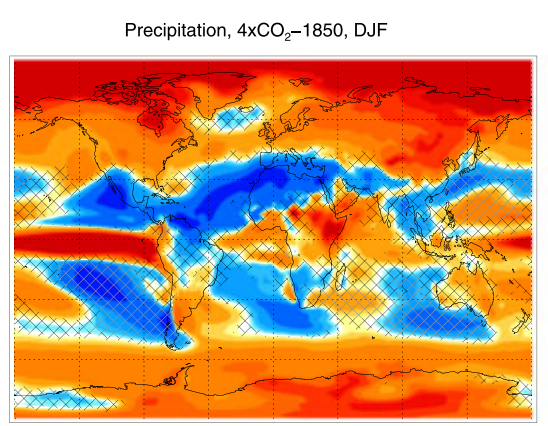

Precipitation, $4 \times \mathrm{CO}_{2}-1850$, JJA

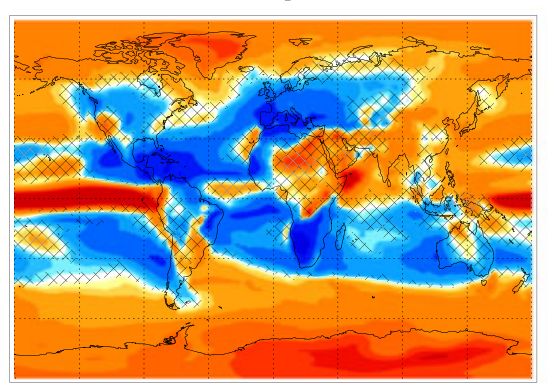

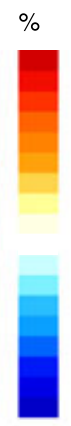

$\%$

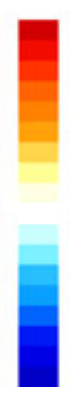

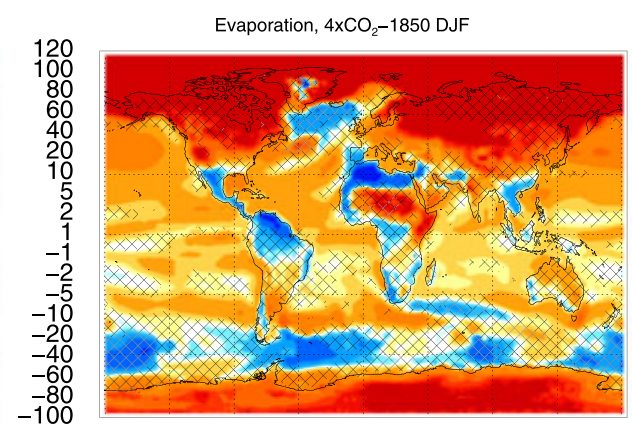

Evaporation, $4 \times \mathrm{CO}_{2}-1850 \mathrm{JJA}$

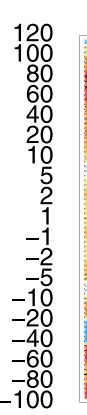

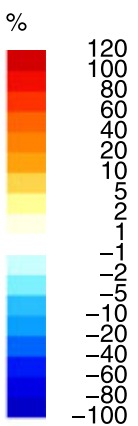

$\%$

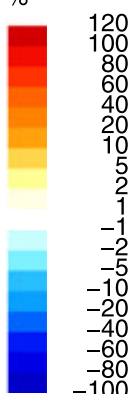

Figure 3. Ensemble mean seasonal differences between $4 \times \mathrm{CO}_{2}$ and 1850 experiments of (left column) precipitation and (right column) evaporation for (top row) December-January-February (DJF) and (bottom row) June-July-August (JJA). All available ensemble members for each model and all years are considered, besides the first 10 years for the $4 \times \mathrm{CO}_{2}$ experiment. Hashed areas indicate locations where less then $75 \%$ of the models agree on the sign of change.

simulation, reduced evapotranspiration is responsible for the reduction of upwelling latent heat flux over land with consequences for precipitation and surface temperatures, but with little change over the ocean. Cao et al. [2012] have further shown that these initial changes occur within days of the simulation using a different model.

[22] The reduction in precipitation for $\mathrm{G} 1$ experiments is therefore largely influenced by $\mathrm{CO}_{2}$ concentration changes. This is discussed by Fyfe et al. [2013]. Models that do not include the interactive land carbon cycle, and therefore do not consider stomatal conductance, simulate smaller reductions in precipitation than those that include this process. These findings are also in agreement with the GeoMIP results, showing the smallest fast precipitation response to $\mathrm{CO}_{2}$ for the EC-EARTH DMI (Figure 2), the only model that does not include this process. If the evapotranspiration from plants scale inversely with $\mathrm{CO}_{2}$ concentration, we also expect precipitation in transient SRM model experiments to vary inversely with $\mathrm{CO}_{2}$. Nevertheless, changes in surface temperature are the most important factor that control changes in maximum precipitation events on the large scale, as was already found in $\mathrm{CO}_{2}$ ramp-up and down experiment by Boucher et al. [2012].

[23] Therefore, even though global surface temperatures do not generally change in G1 compared to 1850 conditions, precipitation changes are a likely result of both the influences of changes in atmospheric stability and stomatal conductance over land. Since we do not find a correlation between precipitation reduction in the G1 experiment and climate sensitivity, we report absolute precipitation and evaporation changes for the $4 \times \mathrm{CO}_{2}$ and the G1 experiments rather than those normalized by temperature changes [see Bala et al., 2008].

\section{Precipitation and Evaporation Response in Tropics and Midlatitudes}

[24] Large regional changes in precipitation and evaporation occur in the two experiments with variability in both sign and magnitude across models (Figures 3 and 4). In the remainder of the text, model responses are always shown in comparison to 1850 conditions. For $4 \times \mathrm{CO}_{2}$, Figure 3 , the largest increase in precipitation occurs in the winter $\mathrm{NH}$ and in the tropical Pacific region, consistently for at least $75 \%$ of all the models. Reductions in precipitation occur in the subtropics and over North America and Europe in summer. Evaporation is increased in high latitudes in both winter and summer and over most of the ocean, while some regions over land, for instance over North Africa and Central America, and Western Europe in summer, show a consistent decrease across at least $75 \%$ of the models. For G1, precipitation and evaporation are strongly decreased in the tropics and in the Northern Hemisphere midlatitudes in summer. Increasing ensemble mean precipitation in high latitudes and the subtropics is to the most part not consistent across models. Evaporation is more strongly increased over land areas than over the ocean, as illustrated by considering zonal averages.

[25] Zonal mean precipitation and evaporation responses in the $4 \times \mathrm{CO}_{2}$ and $\mathrm{G} 1$ experiments are derived for land and ocean separately (Figure 5). Precipitation decreases in G1 over both land and ocean, with similar latitudinal structure. The strongest reduction occurs in the tropics and northern midlatitudes (as further discussed below). Changes in the $4 \times \mathrm{CO}_{2}$ experiment are relatively large and exhibit distinct latitudinal structure between land and ocean. Further, evaporation is significantly smaller over land compared to the ocean for both the $\mathrm{G} 1$ and the $4 \times \mathrm{CO}_{2}$ experiments. 


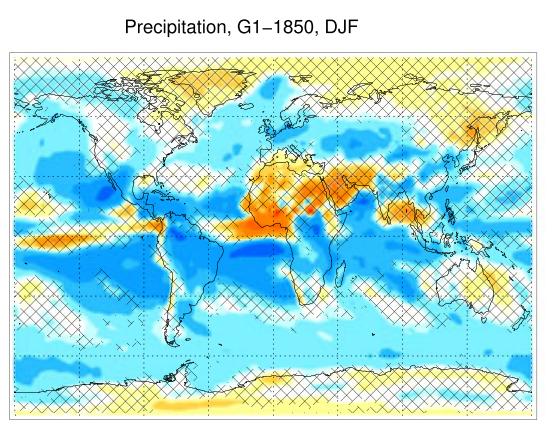

Precipitation, G1-1850, JJA

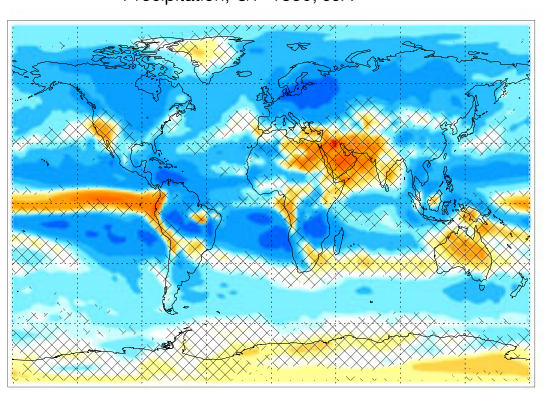

$\%$

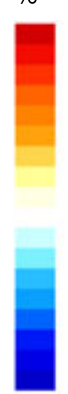

$\%$

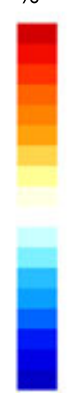

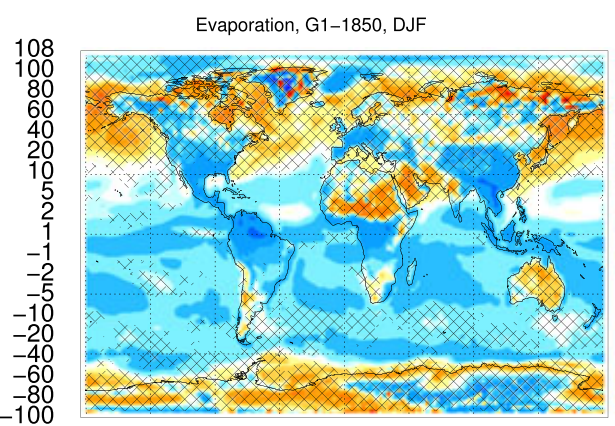

Evaporation, G1-1850, JJA

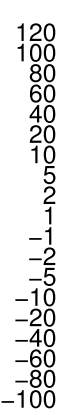

$\%$

120
100
80
60
40
20
10
5
2
1
-1
-2
-5
-10
-20
-40
-60
-80
-100

$\%$

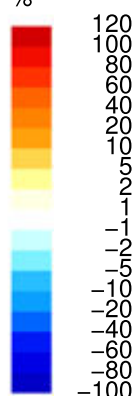

Figure 4. Ensemble mean seasonal differences between G1 and 1850 experiments of (left column) precipitation and (right column) evaporation for (top row) DJF and (bottom row) JJA. All available ensemble members for each model and all years are considered. Hashed areas indicate locations where less than $75 \%$ of the models agree on the sign of change.
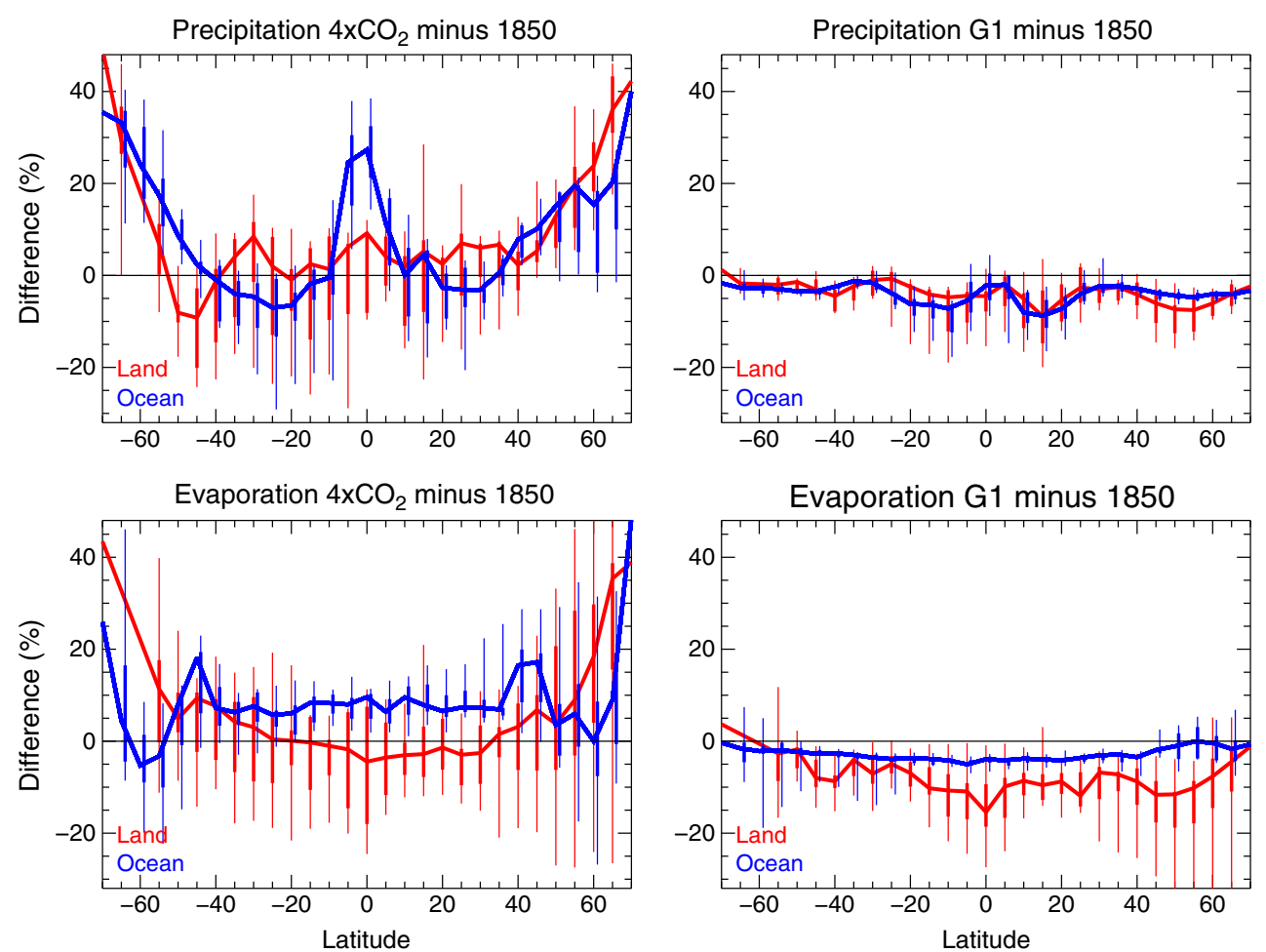

Figure 5. Annually averaged multimodel median zonal changes over land (red solid line) and over the ocean (blue solid line) between (left column) $4 \times \mathrm{CO}_{2}$ and (right column) G1 experiments with regard to 1850 conditions for the following variables: relative changes in (top row) precipitation and (bottom row) evaporation. All available ensemble members for each model and all years are considered, besides the first 10 years for the $4 \times \mathrm{CO}_{2}$ experiment. The multimodel ranges of the 5 th and 95th percentile are illustrated as thin vertical lines, the 25 th and 75 th percentile as vertical thicker lines. 


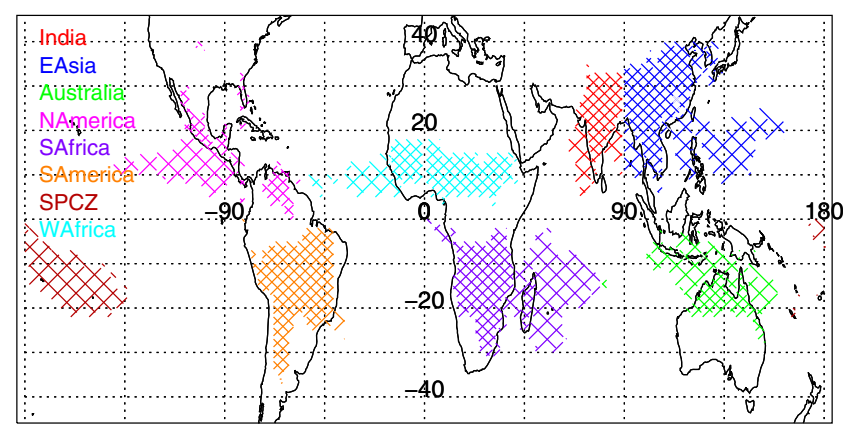

Figure 6. Monsoonal regions (different colors) over land (small hashes) and ocean (large hashes), derived from the Global Precipitation Climatology Project (GPCP) data set [Adler et al., 2003], covering the years 1979-2010, and using criteria described in Wang and Ding [2006], see text for more details. The North and South American monsoons are defined here as the American monsoon North and South of the equator, respectively.

For G1, evaporation decreases by around $10 \%$ over land, while changes over the ocean are small. As discussed above, the physiological impact on evaporation adds an important process that is likely responsible for the disproportional reduction of evaporation over land compared to changes over the ocean. This further coincides with the smallest reduction occurring in the EC-EARTH-DMI in low and midlatitudes (not shown).

[26] With an intensification of the hydrologic cycle in $4 \times \mathrm{CO}_{2}$ conditions, rainfall and evaporation increase generally, with reductions in the subtropics over ocean [e.g., Durack et al., 2012]. The reduction of precipitation in the $25^{\circ} \mathrm{S}-45^{\circ} \mathrm{S}$ latitude band over the ocean coincides with a strong decrease in cloud amount and relative humidity [Fasullo and Trenberth, 2012] and is also connected to poleward shifts in the midlatitude storm tracks [Scheff and Frierson, 2012]. As for G1, the suppressed increase of evaporation over land compared to the ocean is likely amplified by the reduced stomatal conductance of plants in a high $\mathrm{CO}_{2}$

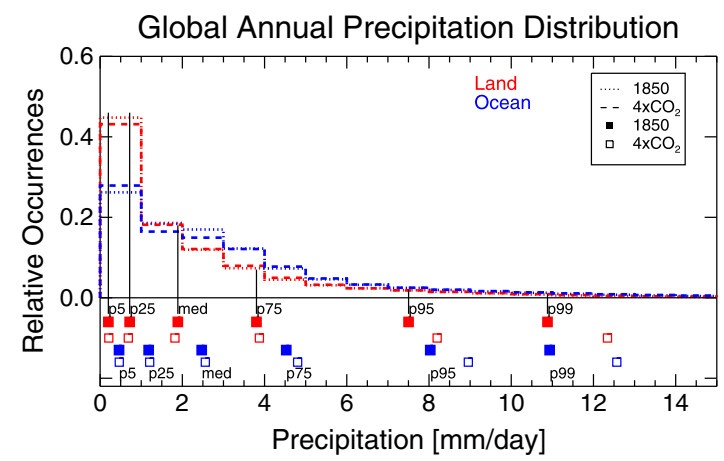

environment contributing to the moisture limitation over land. At high latitudes, increased evaporation likely arises from increases in rainfall and temperature.

[27] In the following, we distinguish between global and regional responses of each experiment, including monsoon components, the tropics, and the midlatitudes. Monsoon components, as shown in Figure 6, are derived using the criteria of Wang and Ding [2006]. These criteria are based on the local annual range (AR) of precipitation, which is defined as the difference between total summer (JJA for the Northern Hemisphere, DJF for the Southern Hemisphere) and winter (DJF for the Northern Hemisphere, JJA for the Southern Hemisphere) precipitation. Regions are defined to be monsoonal if the AR exceeds $180 \mathrm{~mm}$ and the local summer monsoon precipitation comprises at least $35 \%$ of the total annual rainfall [Wang and Ding, 2006]. In addition to the regions identified by Wang and Ding [2006], we consider two subregions of Asia: India and East Asia. These criteria are applied to the GeoMIP simulations and to two independent precipitation data sets (as discussed in section 5.1). The global mean intensity of the summer monsoon precipitation of all identified monsoon components is defined as the global monsoon index (GMI) [Wang and Ding, 2006]. The tropics are defined here as the region between $25^{\circ} \mathrm{N}$ and $25^{\circ} \mathrm{S}$, excluding any monsoonal regions in this latitude band, to distinguish between their respective precipitation responses. We report mean and median values of multimodel results and consider changes to be robust if $75 \%$ of all models agree on the sign of the change. Further, the mean interannual variability of the experiment has to be smaller than the change, compared to the control, to produce a significant result.

[28] We also assess relative changes in frequency of precipitation intensities using monthly-averaged model output to derive seasonal and annual averages, as demonstrated in Figure 7. The shape of the precipitation distribution is obviously not Gaussian, and its statistics can be more precisely expressed in terms of percentiles rather than in the mean of the distribution (Figure 7, lower part). Consideration of changes in the probability density functions (PDFs) helps to identify, for instance, changes in the tail of the distribution,

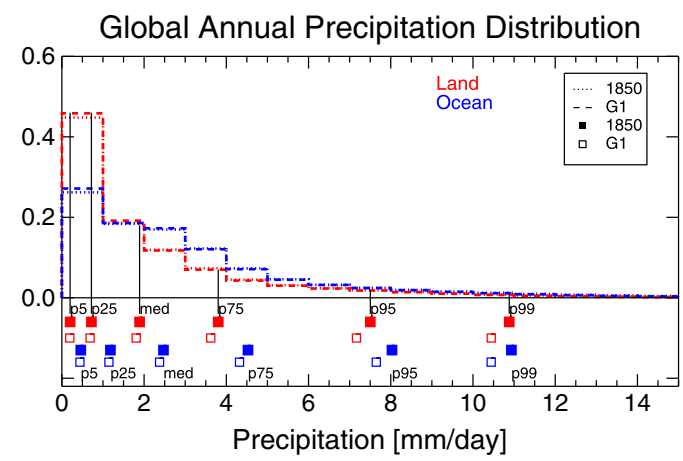

Figure 7. Illustration of statistics for annually averaged multimodel mean probability density function (PDF) of precipitation for (red) land and (blue) ocean. The PDF for the 1850 control experiment is shown as dotted lines, the PDF for the (left) $4 \times \mathrm{CO}_{2}$ and (right) G1 experiments are shown as dashed lines. The statistics of each distribution are described in median and percentiles for each PDF. As an example, the median and percentiles of the PDF for 1850 over land (red dotted line) are marked as black lines in both panels. The corresponding values are illustrated as red filled squares in the lower part of the figure. Corresponding values for the ocean are shown as blue filled squares, and open colored squares for the other distributions $\left(4 \times \mathrm{CO}_{2}\right.$ PDF: left, G1 PDF: right). 
Table 3. Global Averaged Precipitation With Global, Land, and Ocean Averages (in millimeter day ${ }^{-1}$ ) for 1850 Control Simulations and Percent Change of Global Precipitation of $4 \times \mathrm{CO}_{2}$ and G1 Simulations Compared to the 1850 Control Case ${ }^{\mathrm{a}}$

\begin{tabular}{|c|c|c|c|c|c|c|c|c|c|}
\hline \multirow[b]{2}{*}{ Model } & \multirow{2}{*}{$\frac{1850}{\text { Global }}$} & \multicolumn{2}{|c|}{$\left(\mathrm{mm}\right.$ day $\left.^{-1}\right)$} & \multirow{2}{*}{$\begin{array}{l}4 \times \mathrm{CO}_{2} \\
\text { Global }\end{array}$} & \multicolumn{2}{|c|}{ (\% Change) } & \multirow{2}{*}{$\frac{\mathrm{G} 1}{\text { Global }}$} & \multicolumn{2}{|l|}{ (\% Change) } \\
\hline & & Land & Ocean & & Land & Ocean & & Land & Ocean \\
\hline BNU-ESM & 3.01 & 2.90 & 3.22 & $7.5(8.5)$ & 6.9 & 6.3 & -2.0 & -1.4 & -2.6 \\
\hline CanESM2 & 2.74 & 2.13 & 3.08 & $7.4(8.6)$ & 2.2 & 7.6 & -4.7 & -6.9 & -4.2 \\
\hline CESM-CAM5.1 & 3.03 & 2.59 & 3.30 & $6.7(7.4)$ & 8.4 & 5.2 & -5.7 & -5.3 & -5.6 \\
\hline CCSM4 & 2.93 & 2.85 & 3.12 & $6.3(7.4)$ & 8.0 & 4.9 & -4.6 & -2.1 & -5.2 \\
\hline EC-EARTH DMI & 2.84 & 2.40 & 3.13 & 8.1 & 6.5 & 7.8 & -3.4 & -3.1 & -3.5 \\
\hline GISS-E2-R & 3.17 & 3.01 & 3.40 & 1.7 & -5.4 & 3.6 & -6.4 & -10.5 & -4.6 \\
\hline HadGEM2-ES & 3.09 & 2.70 & 3.43 & $5.9(7.1)$ & -0.6 & 7.3 & -4.3 & -3.1 & -4.7 \\
\hline HadCM3 & 2.87 & 2.58 & 3.11 & $4.5(5.5)$ & -2.2 & 5.8 & -4.6 & -3.6 & -4.8 \\
\hline IPSL-CM5A-LR & 2.66 & 2.27 & 3.00 & 11.4 (11.9) & 7.9 & 12.4 & -6.1 & -10.1 & -4.3 \\
\hline MIROC-ESM & 2.80 & 2.74 & 2.93 & $10.6(11.0)$ & 3.7 & 11.0 & -3.1 & -3.7 & -2.8 \\
\hline MPI-ESM-LR & 2.92 & 2.30 & 3.26 & $8.7(9.9)$ & 1.9 & 9.5 & -3.8 & -2.5 & -3.9 \\
\hline NorESM1-M & 2.81 & 2.76 & 2.97 & $5.0(6.0)$ & 7.4 & 3.5 & -5.1 & -2.9 & -6.0 \\
\hline Model Mean & 2.91 & 2.61 & 3.16 & 6.9 & 3.7 & 7.0 & -4.5 & -4.5 & -4.3 \\
\hline GPCP (present) & 2.60 & 2.45 & 2.76 & & & & & & \\
\hline
\end{tabular}

${ }^{\text {a}}$ First ten years of each $4 \times \mathrm{CO}_{2}$ ensemble are disregarded in the values shown here, and averages over years 101-150 are shown in brackets (fifth column). Estimates from Global Precipitation Climatology Project (GPCP) data set (between 1979 and 2010) [Adler et al., 2003] are $2.60 \pm 0.03 \mathrm{~mm} \mathrm{day}^{-1}$ globally, $2.45 \pm 0.05 \mathrm{~mm}$ day ${ }^{-1}$ over land, and $2.76 \pm 0.03 \mathrm{~mm} \mathrm{day}^{-1}$ over the ocean.

similar to the method of $O^{\prime}$ Gorman [2012]. For the global average, the $4 \times \mathrm{CO}_{2}$ simulations have significantly more frequent occurrences of large monthly mean precipitation events than the control simulations; the G1 experiments are much closer to the control for the 99th percentile, and SRM has generally a reduced probability of extreme precipitation events. A detailed assessment of changes in extreme precipitation events, drizzle, and storms, on a daily basis, is beyond the scope of this work and will be performed in future studies.

\subsection{Large-Scale Features and Tropical Response}

[29] For the $4 \times \mathrm{CO}_{2}$ experiment, the global multimodel mean (MMM) precipitation over land is $0.10 \mathrm{~mm}$ day $^{-1}$ (3.7\%) larger compared to the control (Table 3, third column), with an agreement in sign for less than $75 \%$ of the models, as indicated by the quartiles in Figure 8 (top and middle panels). The three models show a decrease of precipitation over land in the $4 \times \mathrm{CO}_{2}$ experiment (see Table 3 ). The GISS model simulates the largest global reduction over land, aligned with the largest fast response (as discussed above) and a stronger reduction in evaporation over land compared to the other models. Over the ocean, models show a robust increase of $0.22 \mathrm{~mm} \mathrm{day}^{-1}(7.0 \%)$ compared to the control simulation (Figure 8, top and middle panels). In contrast, precipitation for the G1 experiment decreases robustly by $0.12 \mathrm{~mm} \mathrm{day}^{-1}(4.5 \%)$ over land and $0.14 \mathrm{~mm}$ day $^{-1}(4.3 \%)$ over the ocean (Table 3$)$. Global precipitation changes of $6.9 \%$ for the $4 \times \mathrm{CO}_{2}$ experiment are smaller than reported in [Schmidt et al., 2012], especially over land, due to the inclusion of additional models and a different averaging of years, as discussed above. The global response in G1 of 4.5\% is in good agreement with findings in Schmidt et al. [2012]. However, reductions over land are significantly smaller in this study including more models. The multimodel median global precipitation changes (Figure 8, dark red for land and grey squares for the ocean) are different from the MMM values, because outliers are valued less in this measure. Multimodel median precipitation changes over land and ocean in the $4 \times \mathrm{CO}_{2}$ are more similar to each other than considering the MMM, with values of around $6.5 \%$ over land and $7.3 \%$ over the ocean. For G1, the multimodel median precipitation reduction is $3.6 \%$ over land and $4.6 \%$ over the ocean. Therefore, MMM precipitation reduction over land for both experiments is amplified by the outliers.

[30] For regional changes, we only report multimodel median precipitation changes. A large portion of global precipitation occurs over monsoonal regions and the tropics (Figure 8, top and middle panels). An increase in precipitation is simulated in $4 \times \mathrm{CO}_{2}$ in both monsoonal land and ocean regions of $0.19 \mathrm{~mm} \mathrm{day}^{-1}(5.2 \%)$ and $0.32 \mathrm{~mm} \mathrm{day}^{-1}$ $(8.1 \%)$, respectively, and in oceanic tropical regions of 0.22 $\mathrm{mm}$ day $^{-1}(5.3 \%)$. This increase is qualitatively consistent with what was found in the CMIP3 archive by Fasullo [2012] and the CMIP5 archive by Hsu et al. [2013] and Lee and Wang [2012]. Over tropical land regions, the multimodel median precipitation increased by $0.15 \mathrm{~mm} \mathrm{day}^{-1}(6.7 \%)$, however, the sign of projected precipitation changes is not consistent among models. The limited extent of the land monsoon region and its associated susceptibility to internal variability of this region might cause these inconsistencies. In contrast, the G1 simulations show a robust decrease in monsoonal precipitation of $0.16 \mathrm{~mm} \mathrm{day}^{-1}(4.5 \%)$ over land and $0.18 \mathrm{~mm} \mathrm{day}^{-1}(4.5 \%)$ over the ocean (Figure 8, top and middle panels). Precipitation in the tropics is reduced by around 5\% with a larger interannual variability and spread among the models over land compared to the ocean. Deviation from preindustrial values is slightly smaller in $\mathrm{G} 1$ than for the $4 \times \mathrm{CO}_{2}$ simulations.

[31] For the $4 \times \mathrm{CO}_{2}$ experiment, evaporation increases globally, particularly in the tropics over the ocean between 6 and $10 \%$ while it does not significantly change over land (Figure 8, bottom panel, left symbols of each region), in agreement with earlier work [Held and Soden, 2006; Seager et al., 2010]. These studies show that reductions in $P-E$ over the ocean and increases over land in the tropics take place in a warming climate. For the G1 experiment, evaporation decreases monotonically over both land 
$\left(4 \times \mathrm{CO}_{2}\right.$ and $\left.\mathrm{G} 1\right)$ minus 1850
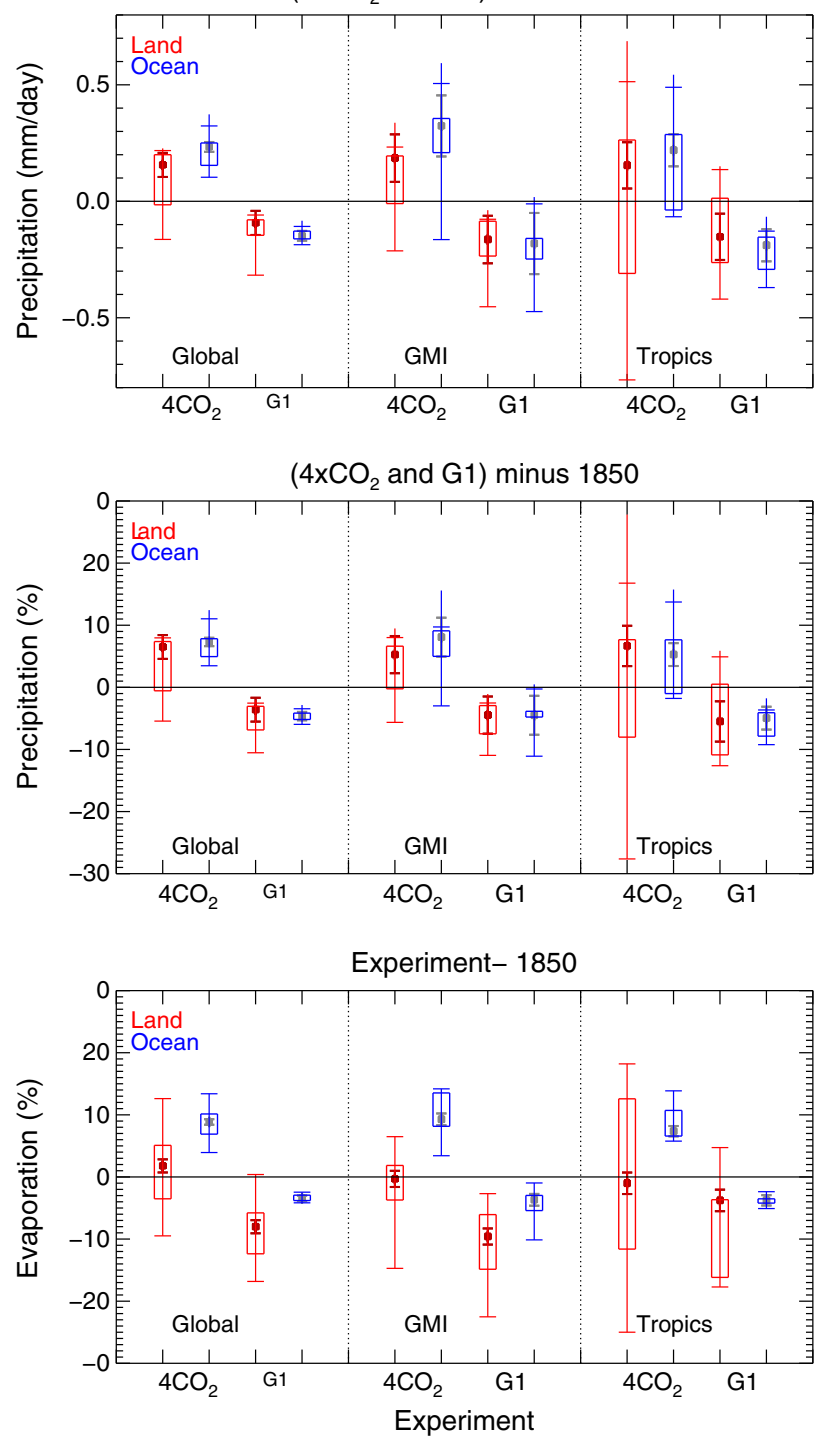

Figure 8. (top) Annually averaged absolute and (middle) relative change of precipitation and (bottom) evaporation for $4 \times \mathrm{CO}_{2}$ and $\mathrm{G} 1$ with regard to 1850 conditions. Results are for land (red) and ocean (blue) and for different regions: (left) global, (middle) global monsoon index (GMI), and (right) tropical averages, excluding monsoon regions. All available ensemble members for each model and all years are considered, besides the first 10 years for the $4 \times \mathrm{CO}_{2}$ experiment. The multimodel range is illustrated by a vertical line, the 25th and 75th percentile of multimodel results are illustrated as a colored box, and the 5 th and 95 th percentile are illustrated as horizontal bars. In addition, the multimodel median is shown as solid symbols and the interannual variability of each experiment, represented by the median standard deviation of annual averages for each model, is shown as error bars pointing off the median of the multimodel results (dark red for land and grey for ocean). The two left whisker plots for each region indicate the $4 \times \mathrm{CO}_{2}$ statistics. The two rightmost whisker plots indicate the G1 statistics. and ocean, with a significantly stronger decrease over land consistently for all the models with values around $10 \%$ over land and 3\% over the ocean (Figure 8, bottom panel, right symbols of each region). The tropics, excluding the monsoonal regions, show a smaller decrease over land in the multimodel mean.

[32] Along with the increase in precipitation for the $4 \times \mathrm{CO}_{2}$ experiment, small to medium precipitation intensity frequencies (below $8 \mathrm{~mm} \mathrm{day}^{-1}$ ) in the monsoon domains and tropics are reduced by $10 \%$ and $20 \%$, respectively (Figure 9, left column). On the other hand, we find a significant increase in the intensity of frequency of heavy precipitation (99th percentile of the PDF) reaching values of above $80 \%$ for the monsoon and around $50 \%$ for the tropics (Figure 9, left column).

[33] The relative changes in precipitation frequencies for monsoonal regions in G1 (Figure 9, right column) indicate that the frequency of intense global precipitation is more strongly reduced over land than over the ocean, even though the PDF for the ocean describes a longer tail than for the land. Heavy monsoon rainfall $\left(>10 \mathrm{~mm} \mathrm{day}^{-1}\right)$ over land is reduced in frequency by around $20 \%$ (further discussed in section 5.2). A considerable reduction in frequency of heavy precipitation $\left(>8 \mathrm{~mm}\right.$ day $\left.^{-1}\right)$ over the tropics is found for both land and ocean with values up to $20 \%$ for land and up to $30 \%$ for the ocean for the 99th percentile of the PDF. This reduction in the frequency of precipitation accompanies a pronounced reduction in evaporation. In comparison to the $4 \times \mathrm{CO}_{2}$ simulations, perturbations from preindustrial intensities of heavy precipitation are much smaller in G1.

\subsection{Seasonal Precipitation Response in Midlatitudes}

[34] Precipitation in midlatitudes and high latitudes is influenced by both local temperature and relative humidity changes and by the moisture transport from low to midlatitudes [Trenberth et al., 2003], which vary with season. The strong warming toward higher latitudes in the $4 \times \mathrm{CO}_{2}$ experiment results in increased evaporation and precipitation (as discussed above). In the $45^{\circ} \mathrm{N}-65^{\circ} \mathrm{N}$ latitude band for the $4 \times \mathrm{CO}_{2}$ experiment, a disproportionate increase in frequency of medium intensity precipitation is found over land compared to the ocean in winter (see Figure 10), in alignment with a stronger warming over land than over the ocean (colored diamonds in Figure 10). In addition, heavy precipitation frequencies increase more strongly over the ocean compared to the land (Figure 10, left column). In contrast, the frequency of summer median precipitation of 1-3 $\mathrm{mm}^{\text {day }}{ }^{-1}$ is reduced for both land and ocean while the frequency of months with heavy precipitation intensities rises above $50 \%$ for the 95th percentile of the PDF. These changes likely result in increased aridity in the region, as higher frequencies of heavy rainfall are generally associated with increased runoff [Trenberth and Dai, 2007].

[35] The response of precipitation and evaporation in G1 is robust and negative for all latitude zones except for southern latitudes of $65^{\circ} \mathrm{S}-90^{\circ} \mathrm{S}$ (not shown). The strongest relative reduction outside the tropics occurs between $45^{\circ} \mathrm{N}$ and $65^{\circ} \mathrm{N}$, with a decrease in precipitation of $7 \%$ over land and $4 \%$ over the ocean (Figure 5 , right column). Seasonal changes are much more pronounced than annual average values (not shown). In summer, a robust reduction of precipitation frequency of around $30 \%$ over land and around $25 \%$ 

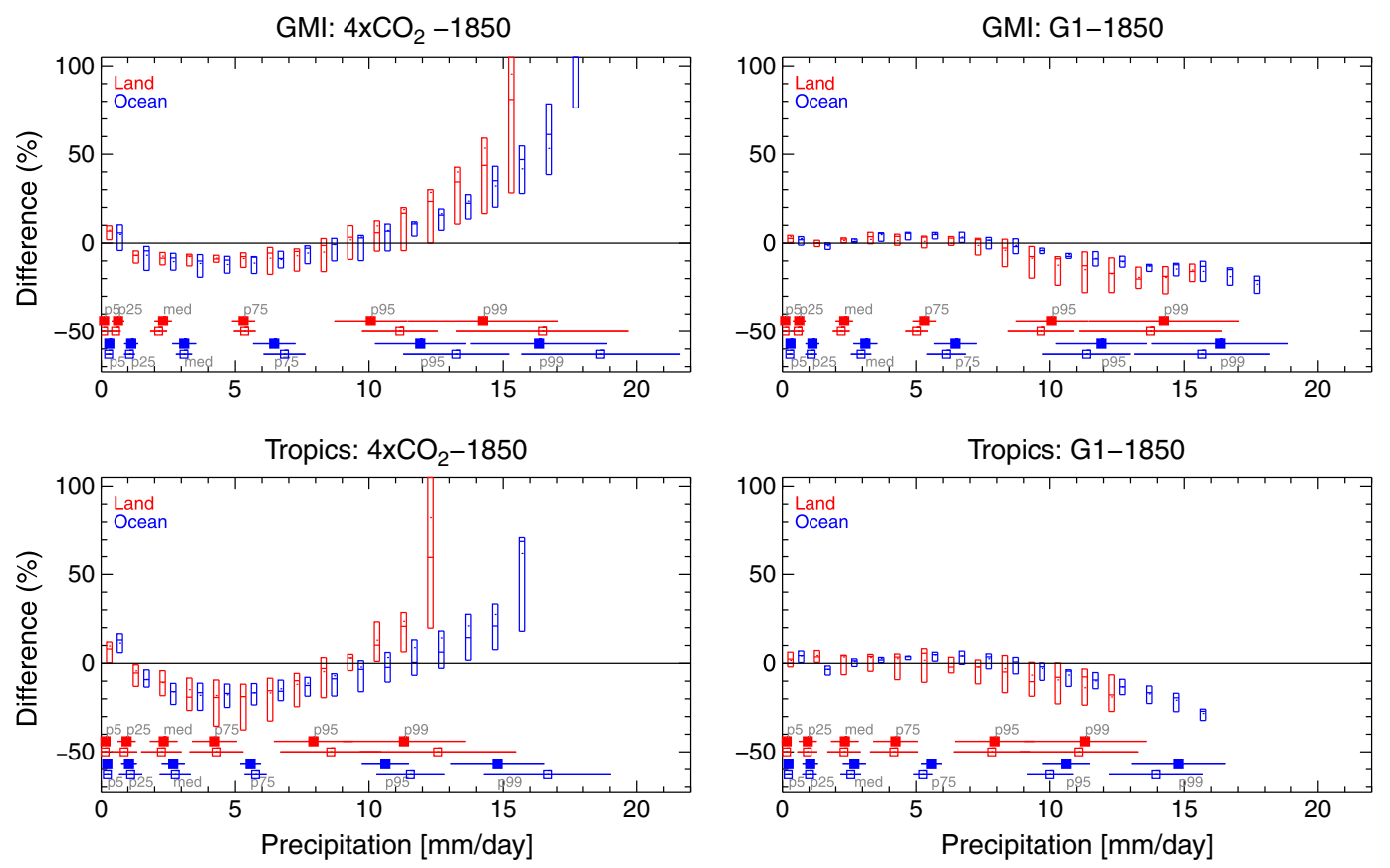

Figure 9. Percent differences of global precipitation frequencies of annually averaged multimodel results for (left column) $4 \times \mathrm{CO}_{2}$ simulations and (right column) G1 simulations with regard to 1850 conditions based on monthly output. Results are for land (red) and ocean (blue) and for different regions consistent with Figure 8. All available ensemble members for each model and all years are considered, besides the first 10 years for the $4 \times \mathrm{CO}_{2}$ experiment. The multimodel median (horizontal line) and the 25th and 75th percentile (box) are illustrated for $1 \mathrm{~mm} \mathrm{day}^{-1}$ precipitation increments. Due to the small fraction of the PDFs that occur for very large precipitation events, relative changes of all the bins covering precipitation events above the 99th percentile are combined into one in this analysis. Statistics of the precipitation distributions of each experiment are added, as shown in Figure 7, with filled symbols illustrating the control and open symbols the experiment. The range of the results from different models (standard deviation) is shown as horizontal error bars.
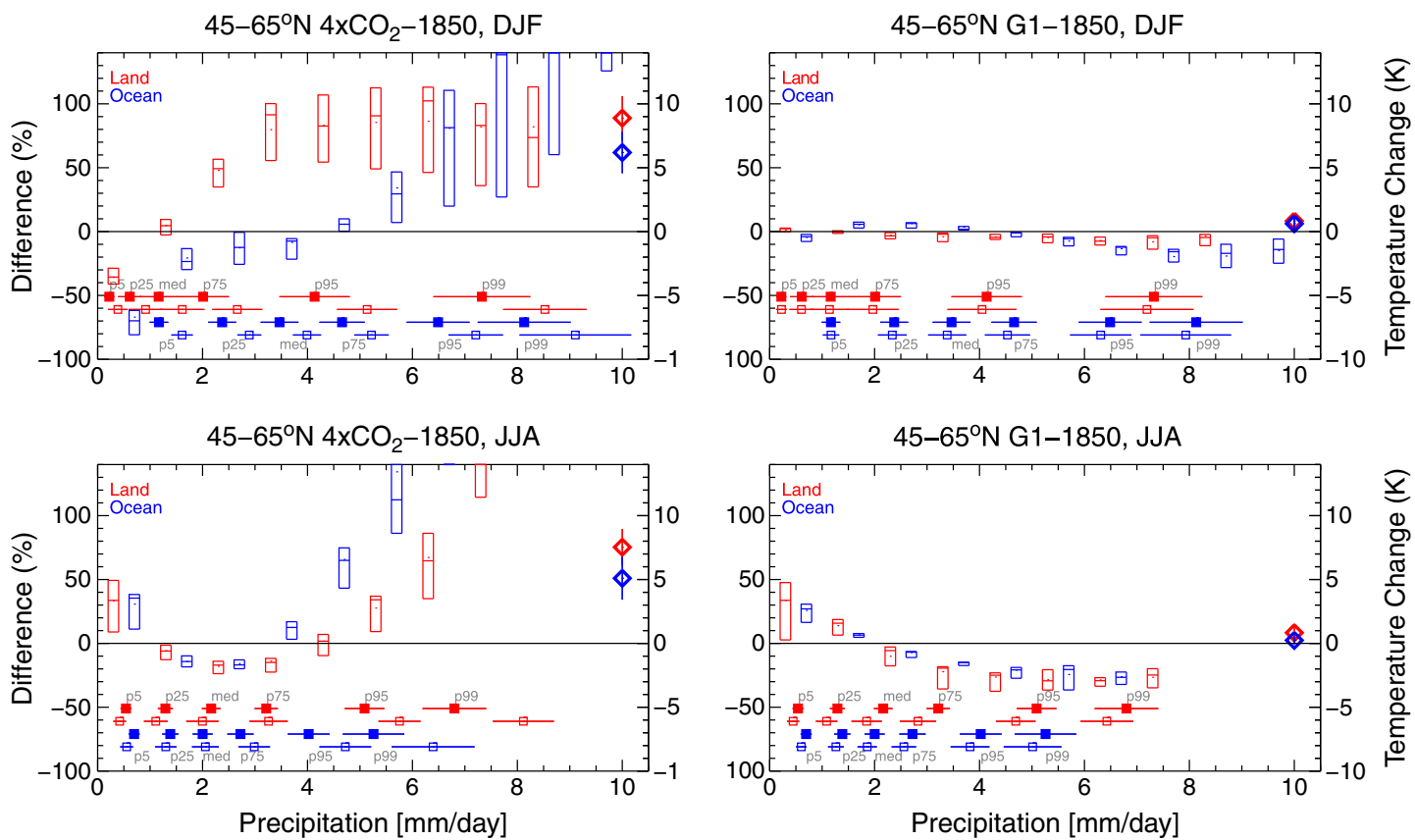

Figure 10. As Figure 9, but for seasonal and zonal averages between $45^{\circ} \mathrm{N}$ and $65^{\circ} \mathrm{N}$ for winter (DJF) and summer (JJA). In addition, temperature changes of seasonal and zonal averages are shown as colored diamonds on the right of each plot, the range of different models (standard deviation) is shown as an error bar. 

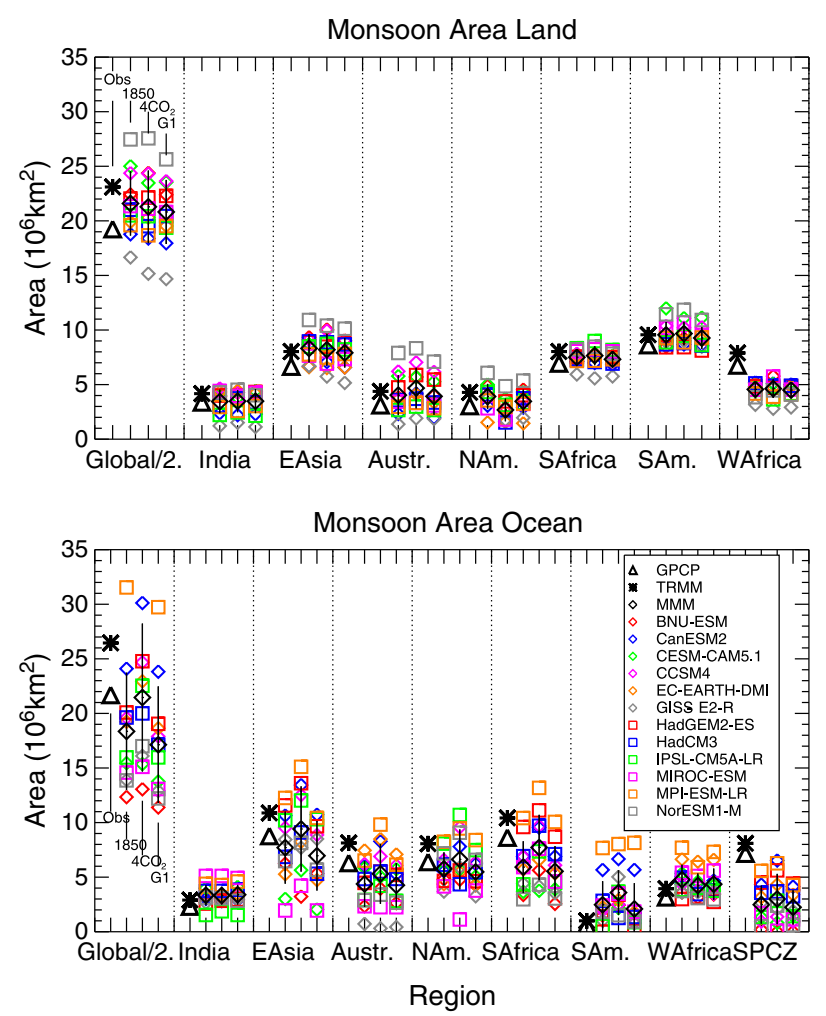

Figure 11. Areas of monsoonal regions derived from 12 climate models (different colors and symbols) following the criteria described in Wang and Ding [2006], for (top) land and (bottom) ocean and for different experiments (left symbol in each cluster: 1850 control; middle symbol in each cluster: $4 \times \mathrm{CO}_{2}$; right symbol in each cluster: G1). All available ensemble members for each model and all years are considered, besides the first 10 years for the $4 \times \mathrm{CO}_{2}$ experiment. MMM values are illustrated as black diamonds for each experiment. Areas of monsoonal regions are also shown for the Global Precipitation Climatology Project (GPCP) data set [Adler et al., 2003], black triangles, and for the Tropical Rainfall Measuring Mission (TRMM) data set [Liu et al., 2012], black asterisks. See Figure 6 for a definition of regions.

over the ocean is simulated for months with precipitation intensities between 3 and $7 \mathrm{~mm} \mathrm{day}^{-1}$. This reduction occurs even though temperatures are about half a degree warmer in midlatitudes over land for this season. On the other hand, precipitation changes are rather small in winter. The strong reduction of the frequency of medium and heavier precipitation (Figure 10, right column) at $45^{\circ} \mathrm{N}-65^{\circ} \mathrm{N}$ over land coincides with a suppression of clouds, as pointed out by Schmidt et al. [2012].

\section{Monsoonal Regions}

\subsection{Evaluation of Precipitation in Monsoonal Regions}

[36] Detailed evaluation of the representation of the global monsoon for a more complete set of CMIP5 models is given in Hsu et al. [2013], Lee and Wang [2012], and Sperber et al. [2012]. Here, we focus on evaluating the simulated monsoon areas (shown in Figure 6) and seasonality of precipitation in GeoMIP models using two precipitation data sets, the Global Precipitation Climatology Project (GPCP) and the Tropical Rainfall Measuring Mission (TRMM) [Liu et al., 2012]. The GPCP data set is based on merged multispectral satellite retrievals and surface observations between 1979 and 2010 [Adler et al., 2003]. TRMM precipitation estimates are derived from merging satellite radar retrievals with surface gauge estimates [Huffman et al., 2009]. While the TRMM estimates are not global, they do cover latitudes of the major monsoon systems. Both data sets have shortcomings related to their ability to detect shallow and extratropical rainfall, and distinguish between suspended and falling hydrometeors. Recent work has suggested that, as a result, these products systematically underestimate rainfall amounts Stephens et al. [2012], though it remains a challenge to balance the surface energy budget under these assumptions. Consistent with this, models simulate larger rainfall amounts than the retrieval estimates by an average of $0.3 \mathrm{~mm} \mathrm{day}^{-1}$ or $12 \%$ (see Table 3, second column); however, much of this excess rainfall is associated with known biases in their representation of the Intertropical Convergence Zone [e.g., Lin, 2007; Zheng et al., 2012]. As such, resolving these issues lies beyond the scope of this manuscript and the range of observations will be estimated here using GPCP and TRMM data sets. Even though the period of observed precipitation does not coincide with the experiments performed, evaluation of its large-scale features is possible since changes across the experiments are in general less than the differences between the two observational data sets (see Figure 11).

[37] The MMM area of the global land monsoon for all three experiments is similar to that observed, but the global ocean monsoon area is smaller for most models (Figure 11). The monsoon domain was shown to not change appreciably over land with increasing $\mathrm{CO}_{2}$ concentrations, besides some changes over Asia were identified [Lee and Wang, 2012], which are not apparent using the GeoMIP models. The largest model spread of the land monsoon extent occurs in East Asia and Australia. The area of the West African land monsoon component is smaller than observed in all models. Over the ocean, the simulated monsoon areas vary more widely across models than over land and simulated ocean

Table 4. Global Land/Ocean Precipitation Ratio for 1850 Control, $4 \times \mathrm{CO}_{2}$, and G1 Simulations and Estimates From Global Precipitation Climatology Project (GPCP) Data Set [Adler et al., 2003]

\begin{tabular}{lccc}
\hline Model & 1850 & $4 \times \mathrm{CO}_{2}$ & $\mathrm{G} 1$ \\
\hline BNU-ESM & 0.90 & 0.91 & 0.91 \\
CanESM2 & 0.69 & 0.66 & 0.67 \\
CESM-CAM5.1 & 0.78 & 0.81 & 0.79 \\
CCSM4 & 0.92 & 0.94 & 0.95 \\
EC-EARTH DMI & 0.77 & 0.76 & 0.77 \\
GISS-E2-R & 0.89 & 0.81 & 0.83 \\
HadGEM2-ES & 0.79 & 0.73 & 0.80 \\
HadCM3 & 0.83 & 0.77 & 0.84 \\
IPSL-CM5A-LR & 0.76 & 0.72 & 0.71 \\
MIROC-ESM & 0.94 & 0.87 & 0.93 \\
MPI-ESM-LR & 0.71 & 0.66 & 0.72 \\
NorESM1-M & 0.93 & 0.96 & 0.96 \\
Model Mean & 0.82 & 0.80 & 0.82 \\
GPCP (present) & 0.89 & & \\
\hline
\end{tabular}



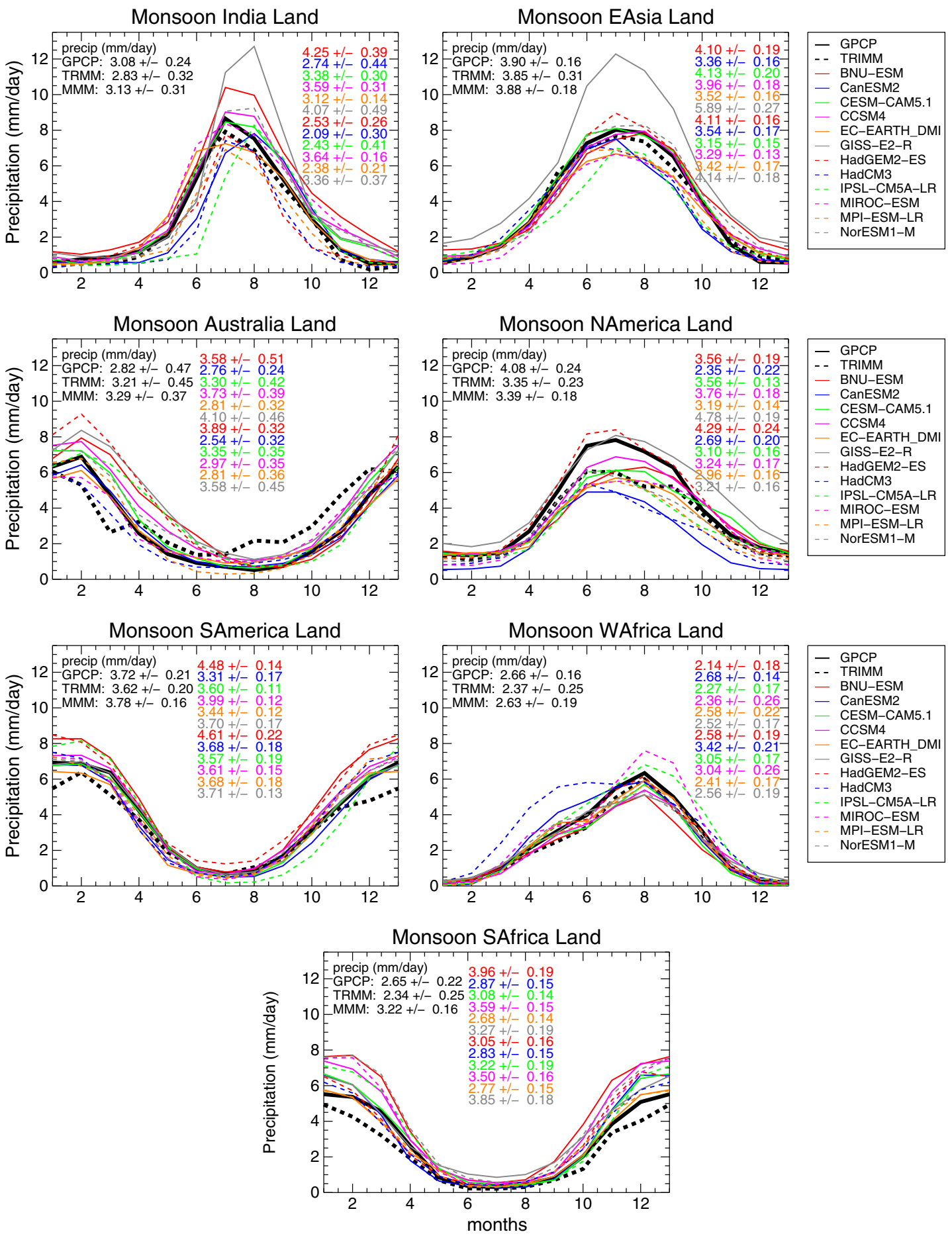

Figure 12. Seasonal cycle of precipitation over monsoonal regions derived from the different GeoMIP model output for the 1850 control simulation (different colors and line styles) and the GPCP (black solid line) and TRMM data set (black dashed line). The total precipitation and the standard deviation of annual averages (interannual variability) over each region and each model are listed in each panel in the color and order prescribed in the legend. Values for the MMM total precipitation and the GPCP and TRMM results are shown in black. See Figure 6 for a definition of regions. 

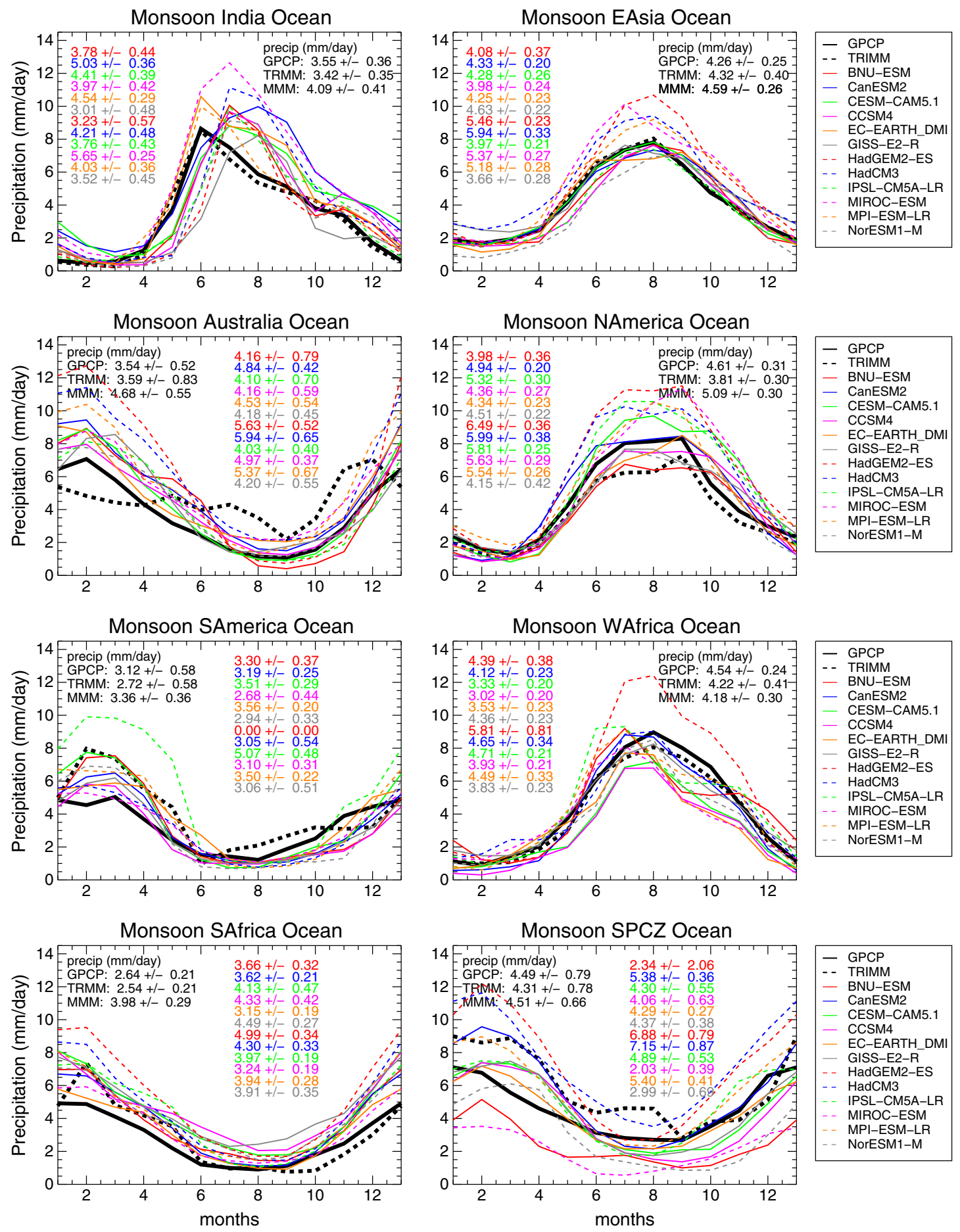

Figure 13. As in Figure 12, but for each monsoonal region over ocean.

monsoonal regions are generally smaller than observed in Australia, South Africa, and the South Pacific Convection Zone (SPCZ) while they are larger than observed in South America. For these regions, it is known that model biases are characterized by an excessive Pacific cold tongue and Atlantic zonal gradient. Under G1 forcing, the area of the monsoonal regions decreases over both land and ocean, generally, while for $4 \times \mathrm{CO}_{2}$ conditions, increases in extent are simulated over ocean. The observed land-to-ocean ratio of global precipitation of 0.89 (for GPCP) is on average $7 \%$ smaller in models and falls below 0.80 in half of the models in the GeoMIP archive, resulting in a MMM of 0.82 (Table 4). For the $4 \times \mathrm{CO}_{2}$ experiment, the models show on average a slight reduction in the land-to-ocean ratio, suggesting a stronger increase of precipitation over the ocean than over land due to moisture constraints over land and additional warming [e.g., Fasullo, 2012]. In the G1 experiments, the land-to-ocean ratio in the MMM does not change significantly and individual models simulate differences in comparison to observations ranging between $-6 \%$ and $3 \%$. 
[38] The seasonal cycle of global monsoon precipitation over land for 1850 control conditions is compared to the two independent precipitation data sets (Figures 12 and 13). The comparison is valid since precipitation changes between 1850 and present day are not expected to be larger than the estimated transient feedback $\left(2-3 \% \mathrm{~K}^{-1}\right)$, which is less than the uncertainty of observations. Model precipitation over land is in general larger than observed in the summer Southern Hemisphere monsoons (Figure 12). Biases and intermodel spread in monthly mean summer precipitation are greater over ocean monsoonal regions, than over land, and are particularly large for the SPCZ (Figure 13). Summer precipitation is larger than reported in observations for the MMM in most regions. The seasonal cycle of the Indian monsoon over ocean has its onset in May and maximum in June, which is delayed in most models, in agreement with the findings by Seth et al. [2010] and Sperber et al. [2012].

[39] The MMM (Figures 12 and 13) and the mean interannual variability of precipitation over monsoonal regions for 1850 control conditions are for most regions within the range of GPCP and TRMM, even though there are large differences between individual models. Simulated deficiencies occur for the Australian, North and South American, and South African land monsoon components and for the South American and SPCZ ocean monsoon. The simulated variability is excessive for the Indian and South African oceans. However, in general, reasonable representation of the monsoon for most models and regions provides confidence in precipitation responses simulated by the models under various GeoMIP forcing scenarios.

\subsection{Precipitation and Evaporation Response in Monsoonal Regions}

[40] The separation of global monsoon precipitation into its regional components enables an assessment of the regional hydrologic responses (Figure 14). We only consider the summer season for each region, the time of maximum precipitation (JJA for the Northern Hemisphere and DJF for the Southern Hemisphere).

[41] For the $4 \times \mathrm{CO}_{2}$ experiment, the median response of all the models is an increase in precipitation for both land and ocean, except for the North American monsoon, where a weakening of the monsoon precipitation is evident, in agreement with Lee and Wang [2012]. In detail for the $4 \times \mathrm{CO}_{2}$ experiment, a robust increase of precipitation by around $0.70-0.90 \mathrm{~mm} \mathrm{day}^{-1}(10 \%)$ occurs over both land and ocean for India and East Asia. A robust decrease of precipitation is simulated for North America over land with values around $0.40 \mathrm{~mm}$ day $^{-1}(7 \%)$, while the model response varies largely over the ocean.

[42] Evaporation for the $4 \times \mathrm{CO}_{2}$ experiment increases over the ocean and does not change over land for most regions (Figure 14, the two left whiskers symbols of each region). A robust decrease in evaporation over land only occurs for the monsoonal region of North America, as overall, the hydrologic cycle strengthens in these simulations. The differences in monsoonal precipitation response over land and ocean in a warming climate and their governing mechanisms are further discussed by Fasullo [2010], and arise in part from the land-ocean contrast in warm-
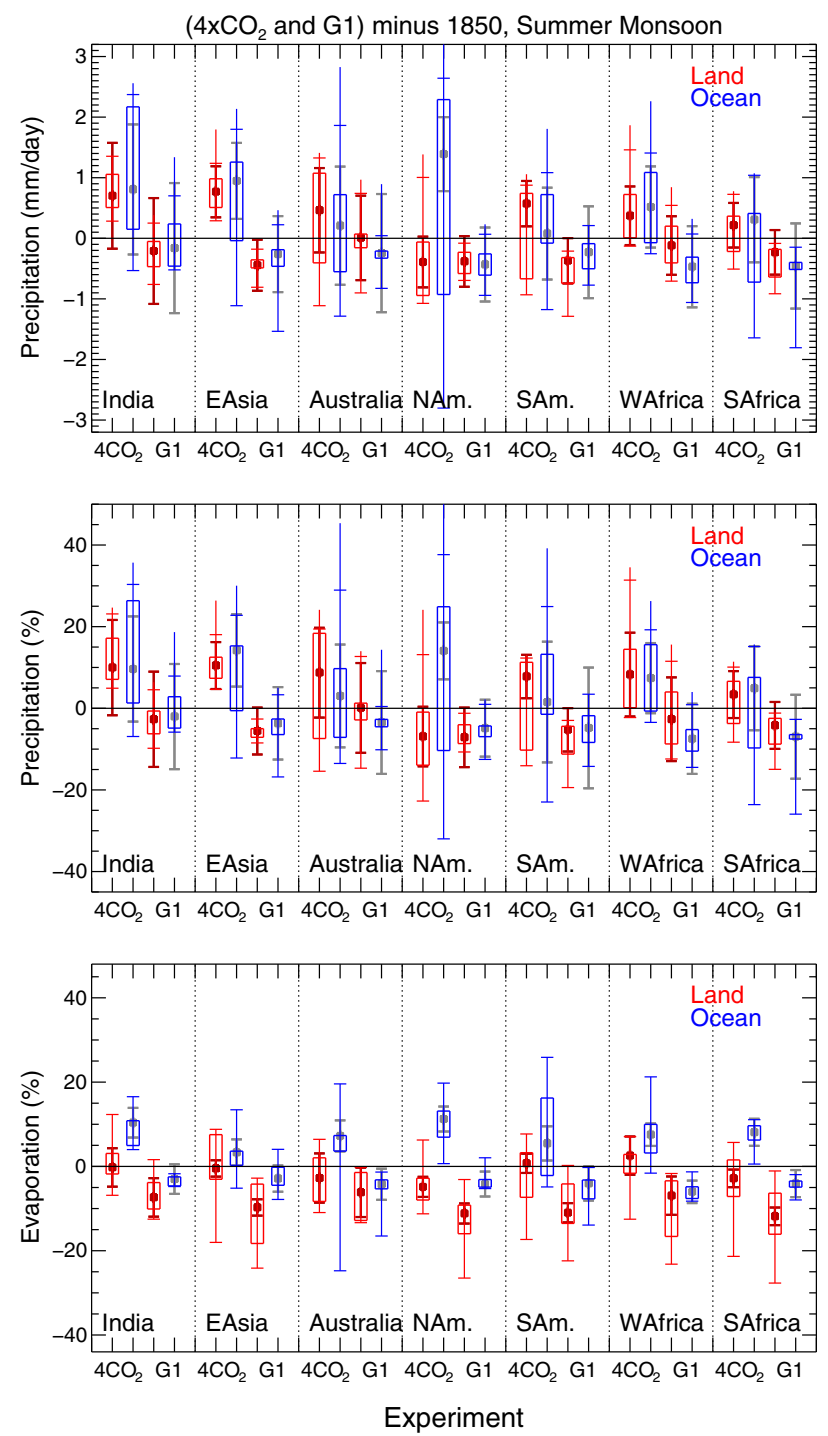

Figure 14. As Figure 8, but for each monsoonal region for summer.

ing and a reduction in evaporation due to reduced stomatal conductance in a high $\mathrm{CO}_{2}$ environment.

[43] For the G1 experiments, a decrease in median precipitation is simulated for all regions except for a zero change for Australia over land (see Figure 14, top and middle panels). In particular, we find a decrease in precipitation over land for East Asia $\left(\approx 0.45 \mathrm{~mm} \mathrm{day}^{-1}, 6 \%\right)$, North and South America $\left(\approx 0.39 \mathrm{~mm} \mathrm{day}^{-1}\right.$ and $0.37 \mathrm{~mm} \mathrm{day}^{-1}$, $7 \%$ and $6 \%$, respectively), where all models agree on the sign of the change, and South Africa $\left(0.23 \mathrm{~mm} \mathrm{day}^{-1}, 5 \%\right)$, where $95 \%$ of the models agree on the sign of the change. The relative multimodel median differences between the G1 and 1850 experiments also exceed the interannual variability of G1 (dark red error bars), reported changes are therefore significant. Precipitation is reduced over India by $\approx 0.21 \mathrm{~mm} \mathrm{day}^{-1}(2 \%)$, with a reduction simulated for more than $75 \%$ of the models. However, due to the large interannual variability, the change is not considered to be significant. Also, precipitation changes over the ocean for 

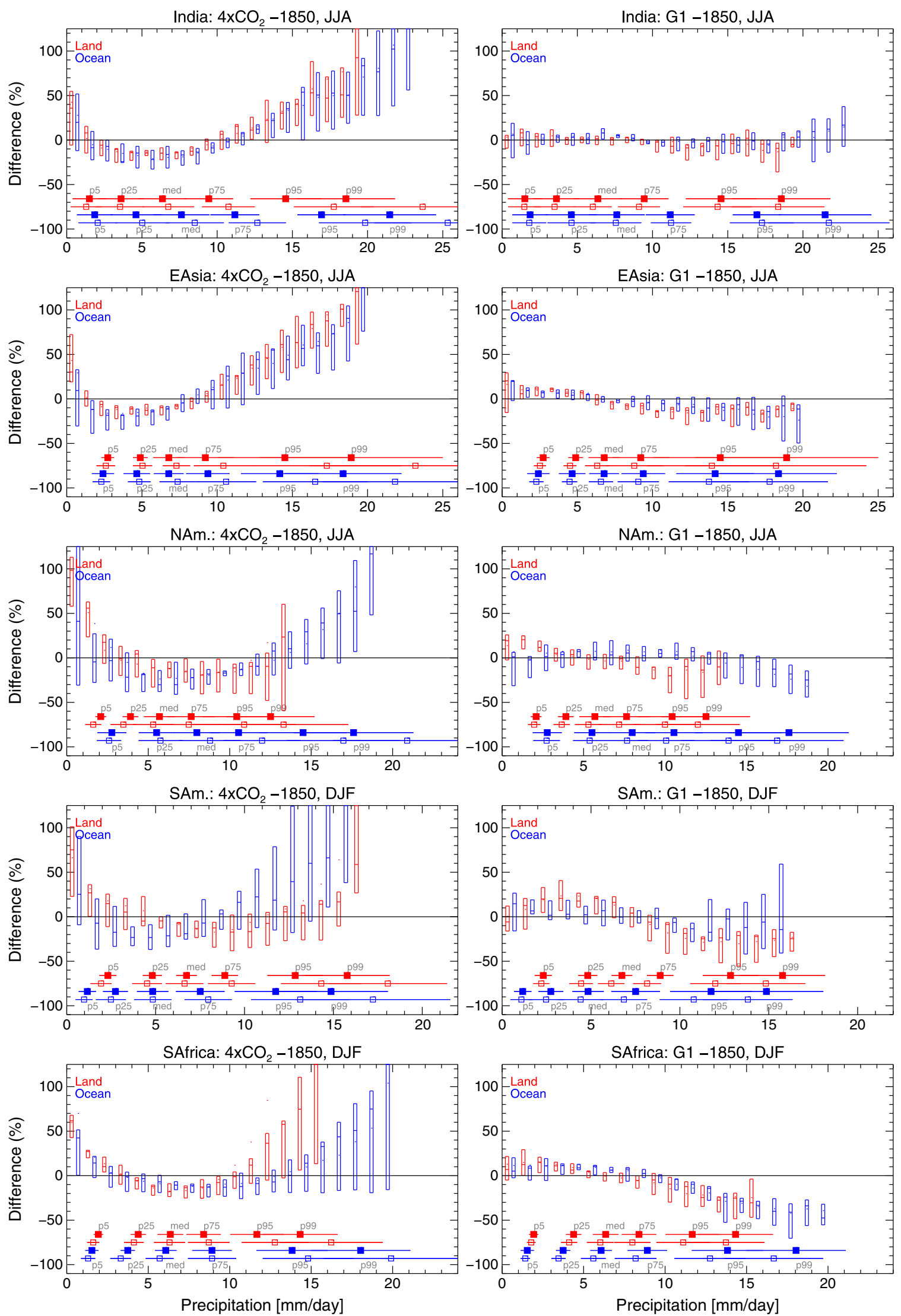

Figure 15. As Figure 9, but for different monsoonal regions and for summer of each region only. 

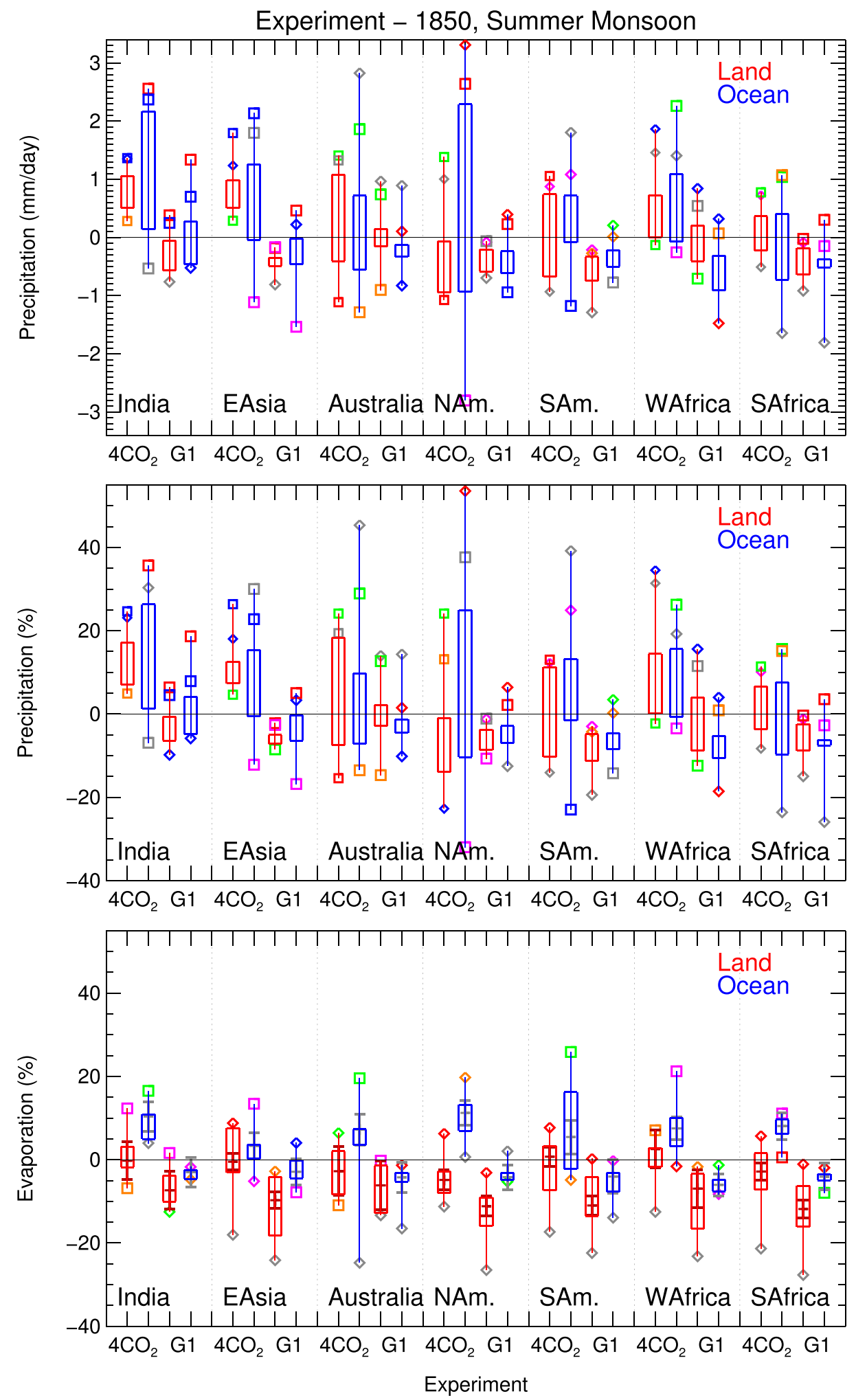

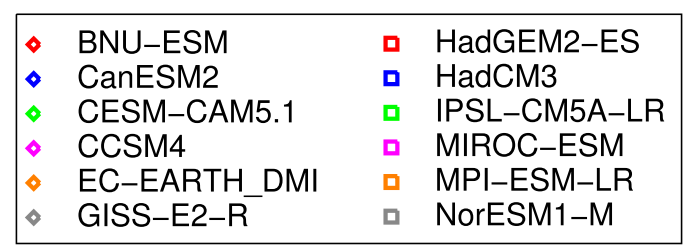

Figure 16. As Figure 14, but with additional information about model results (different symbols) that described value outside the 5 th and 95 th percentile range of the multimodel distribution. 
most regions are not significant due to the large interannual variability.

[44] Departures of the multimodel median precipitation in G1 from the 1850 control over land are much smaller for Australia, West Africa, and Asia than those of the $4 \times \mathrm{CO}_{2}$, but they are at least half as large for East Asia. For the other regions, departures of the multimodel median precipitation in $\mathrm{G} 1$ are similar to those of the $4 \times \mathrm{CO}_{2}$ simulation for North and South America and South Africa, with North America being the only region that shows a change in the same direction for both experiments. Evaporation over land is strongly decreased for all the models in G1 (Figure 14, bottom panel) with strongest reductions over East Asia, North and South America, and South Africa. The disproportionate cooling of the ocean might allow less moisture to be drawn from the ocean, which may in addition to the physiological effect contribute to the reduction of precipitation and evaporation over land [Boos and Kuang, 2010].

[45] The frequency of the precipitation intensity for the $4 \times \mathrm{CO}_{2}$ experiment between the 25 th and 75 th percentile of the PDF is reduced for all regions and models, whereas heavy precipitation frequency increases (Figure 15), as has also been noted in other recent work [Chou et al., 2012]. In some respects, the Asian monsoon is unique as the heating over ocean draws water vapor from the Arabian Sea and the Bay of Bengal to support rainfall over land [Fasullo, 2012], which is likely responsible for the increase in precipitation frequency for months that experience heavy precipitation of more than $10 \mathrm{~mm} \mathrm{day}^{-1}$ over land and ocean (Figure 15, left, first and second rows). The increase in heavy precipitation is limited over land for North and South American monsoon domains. For North America, this results in reduction of precipitation for most models, which may be a result of its negligible ocean component and inland location, where moisture is limited and evapotranspiration is reduced.

[46] In contrast to the $4 \times \mathrm{CO}_{2}$ experiment, the geoengineering simulations show an increase in the frequency of small and medium precipitation intensity that coincides with a slight increase in tropical stability, as discussed above. For all regions considered besides India, the frequency of months with medium to heavy precipitation intensity is reduced, with a larger reduction over land than over the ocean (Figure 15, right). Reductions in the frequency of heavy precipitation over North and South American monsoonal regions are particularly large around $20-30 \%$ for intensities above the 95 th percentile of the distribution.

[47] The spread of the precipitation response across individual models is in general much larger for $4 \times \mathrm{CO}_{2}$ than for G1, suggesting less variability and therefore less uncertainty in the results in signatures of precipitation change in the G1 simulations. Some models are outliers regarding their precipitation and evaporation responses (see Figure 16). The GISS-E2-R model stands out in simulating the largest reduction in evaporation over land for most regions, which is consistent with the largest global precipitation reduction in G1 compared to the other models, as discussed above. EC-Earth and BNU-ESM models show the smallest reduction in evaporation in $\mathrm{G} 1$ and the largest increase for the $4 \times \mathrm{CO}_{2}$ experiment over land. For EC-Earth, this is consistent with the missing stomatal conductance effect with changing $\mathrm{CO}_{2}$ concentrations (as discussed above), while BNU-ESM experienced some warming in G1. However, the extreme behavior in evaporation in these models is not reflected in the monsoonal summer precipitation response for most regions. This is because the monsoonal precipitation is influenced by both local and large-scale processes, due to the complex interactions of the different components that contribute to the hydrological cycle.

\section{Discussion}

[48] The simulated precipitation and evaporation changes in the highly idealized $4 \times \mathrm{CO}_{2}$ and $\mathrm{G} 1$ experiments point to the fact that the hydrological cycle would be perceptibly weakened by SRM in comparison to the 1850 control. Precipitation and evaporation are considerably reduced in $\mathrm{G} 1$, while departures from the preindustrial control are generally smaller than to those that occur in the $4 \times \mathrm{CO}_{2}$ experiment with no geoenginering performed. Further, the expected increase in flooding in a high $\mathrm{CO}_{2}$ environment, especially over the Asian monsoonal regions, is reduced in G1. Instead, a reduction in frequency of heavy precipitation, of much smaller magnitude than in the $4 \times \mathrm{CO}_{2}$ experiment but still considerable, is simulated in G1 compared to the control.

[49] However, from this analysis, it is not clear how simulated changes in the $P-E$ balance are going to impact runoff and soil moisture. These highly uncertain variables depend often on simple parameterizations in climate models [e.g., Trenberth et al., 2003]. Improved and more detailed and complex models are necessary to investigate the full impact of SRM on changes in regional soil moisture and aridity, with inherent consequences for vegetation. In addition, more realistic experiments are required to support these findings, for instance, future transient model simulations with more realistic forcings as designed in other GeoMIP experiments (G3 and G4, described in Kravitz et al. [2011]).

[50] The G1 experiment applies a reduced solar constant to simulate a uniform increase of the Earth's planetary albedo, which might be achieved by placing mirrors into space [e.g., Angel, 2006]. It has to be pointed out that the climate response of such an experiment may be very different from other theoretical experiments where, for instance, stratospheric aerosols are used to increase the planetary albedo. However, such experiments do not usually provide as large negative forcing as G1, due to the potential limitation of the stratospheric aerosol burden with increasing injection amounts [e.g., Heckendorn et al., 2009; Niemeier et al., 2010], thereby making them less useful experiments for examining the gross aspects of hydrological sensitivity of interest here. In addition, stratospheric aerosols result in heating of the stratosphere, particularly in the tropics, and this results in dynamic perturbations [e.g., Stenchikov et al., 2002; Tilmes et al., 2009]. Changes in heating rates in the stratosphere and at the tropopause are likely to further influence the tropospheric lapse rate, which may alter relative humidity and the hydrological cycle. Furthermore, changes in stratospheric and tropospheric chemical composition are likely to interact with radiation and dynamics while, in this study, the impact of increasing $\mathrm{CO}_{2}$ concentration with and without SRM on chemistry is not considered. Finally, the interaction of thermal and hydrological changes with biogeochemical cycles (e.g., of carbon and nitrogen) in the land and ocean in the context of SRM is an interesting topic that requires further investigation. 


\section{Summary}

[51] In this study, we have explored the robustness of the simulated global and regional response of the hydrologic cycle to a reduction of incoming solar radiation. The solar constant was reduced to counteract the radiative imbalance at the top of the atmosphere from quadrupling of preindustrial $\mathrm{CO}_{2}$. The hydrologic response of this experiment compared to 1850 conditions is contrasted to the response of a quadrupling $\mathrm{CO}_{2}$ experiment without solar dimming.

[52] The abrupt increase of $\mathrm{CO}_{2}$ in both $4 \times \mathrm{CO}_{2}$ and G1 experiments leads to an initial decrease of upwelling latent heat flux at the Earth's surface (Appendix A), mainly controlled by the changes in the increase of atmospheric stability, which has a global impact on evaporation. In addition, changes in evapotranspiration over land strongly affect the precipitation over land. These changes have implications for temperatures, clouds, and precipitation.

[53] The response due to the warming in the $4 \times \mathrm{CO}_{2}$ experiment leads to global precipitation increases of 0.10 $\mathrm{mm} \mathrm{day}{ }^{-1}(3.7 \%)$ over land and $0.22 \mathrm{~mm} \mathrm{day}^{-1}(7.1 \%)$ over the ocean, considering the multimodel mean and around $6.5 \%$ over land and $7.3 \%$ over the ocean for the multimodel median. A significant increase in precipitation occurs in midlatitudes and high latitudes and in the tropics, while decreasing precipitation is simulated in the subtropics over the ocean. East Asia and India experience a robust increase of monsoonal precipitation of around $10 \%$. On the other hand, a robust regional reduction in precipitation for the North American summer monsoon of around $7 \%$ over land is simulated. The frequency of weak and medium precipitation intensities is generally reduced for monsoonal regions while the frequency of heavy precipitation is strongly increased which likely results in increased aridity and flooding in these regions.

[54] Solar reduction in G1 is found to significantly impact precipitation and evaporation in both the tropics and midlatitudes. Despite a stabilization of global mean temperatures in $\mathrm{G} 1$, the tropics experience a cooling while high latitudes are warming. This results in a robust (in the sense that most models provide the same signature, unlike the $4 \times \mathrm{CO}_{2}$ simulations) global decrease in precipitation of $0.12 \mathrm{~mm}$ day $^{-1}(4.9 \%)$ over land and $0.14 \mathrm{~mm} \mathrm{day}^{-1}(4.5 \%)$ over the ocean, considering the multimodel mean and $3.6 \%$ over land and $4.6 \%$ over ocean for the multimodel median. Significant changes of precipitation and evaporation are also simulated for midlatitudes, with a maximum precipitation reduction in the $45^{\circ} \mathrm{N}-65^{\circ} \mathrm{N}$ band for $\mathrm{G} 1$ of $7 \%$ over land and $4 \%$ over the ocean. For this region, the frequency of monthly precipitation intensity between 3 and $7 \mathrm{~mm} \mathrm{day}^{-1}$ is reduced by about $30 \%$ over land and $25 \%$ over the ocean in summer, while changes are much smaller in winter. These changes are generally smaller than the changes produced by the $4 \times \mathrm{CO}_{2}$ forcing.

[55] A detailed analysis of monsoonal precipitation and evaporation provides information about regional impacts of geoengineering. The statistics of total precipitation, monsoonal area, and seasonal cycle performed in the control experiments are in general in good agreement with observational estimates for present day conditions using GPCP and TRMM data sets, besides the delay of the onset of the Indian monsoon over the ocean for most models. Further, the simu- lated global land-to-ocean ratio of precipitation is about 7\% smaller compared to observations, due to an overestimate of the amount of the precipitation in various monsoonal regions over the ocean during their peak season. Also, observations might underestimate precipitation in those regions [Stephens et al., 2012]. This may have an impact on the response of the climate forcings in different experiments, but cannot be identified for individual model responses.

[56] Considering the multimodel median and the interannual variability of $\mathrm{G} 1$, we find a robust and significant decrease of monsoonal precipitation over land for East Asia (6\%), North America (7\%), South America (6\%), and South Africa (5\%), and a robust but not significant decrease of $2 \%$ over India. These decreases occur primarily in months with larger precipitation intensities (above the 95th percentile of the precipitation distribution) which experience a robust decrease in frequency of about $20 \%$ for all monsoonal regions. These changes are in general greater over land than over the ocean. Decreases in evaporation of more than $10 \%$ occur over land as compared to $3 \%$ over the ocean. These results support earlier studies [e.g., Robock et al., 2008] that pointed to a significant reduction of monsoon precipitation over Asia and Africa. In addition, other monsoonal regions are impacted by SRM as well.

[57] The resulting weakening of the hydrologic cycle due to SRM in comparison to the control reduces precipitation and evaporation over land by a considerable amount globally and especially in most monsoonal regions and in north midlatitudes. On the other hand, dramatic increases in heavy precipitation globally in the $4 \times \mathrm{CO}_{2}$ experiment and inferred increases in flooding might be prevented by SRM as extreme rainfall intensities are likely to decrease, especially for Asian monsoonal regions, if G1 type geoengineering is to be employed. Changes in soil moisture and implications for agriculture in different regions as a result of SRM should be further investigated using GeoMIP model results. More work is further needed to assess the positive and negative consequences of these changes for the biosphere and society, using more appropriate models and realistic scenarios. In summary, we have shown that even though global temperatures can be approximately balanced in this experiment, the hydrological cycle does not resume control conditions, even though deviations of extremes from the control are in general smaller than in an experiment where no geoengineering is performed.

\section{Appendix A: Importance of an Interactive Land Carbon Cycle to the Surface Energy Budget in CESM4}

[58] The importance of changes in stomatal conductance for the surface energy budget due to abrupt $\mathrm{CO}_{2}$ increase for the $4 \times \mathrm{CO}_{2}$ and $\mathrm{G} 1$ experiments is discussed here in the context of additional CCSM4 simulations. Changes during the first year of each GeoMIP simulation (Figure A1) are contrasted to simulations that assume background $\mathrm{CO}_{2}$ levels in the land component of the model and therefore ignore the impact of $\mathrm{CO}_{2}$ on the stomatal conductance (Figure A2).

[59] The responses of surface fluxes of latent heat (LH) and sensible heat $(\mathrm{SH})$, and relative humidity $(\mathrm{RH})$ are very similar in the GeoMIP G1 and $4 \times \mathrm{CO}_{2}$ simulations (Figures A1 and A2), even though the downwelling 

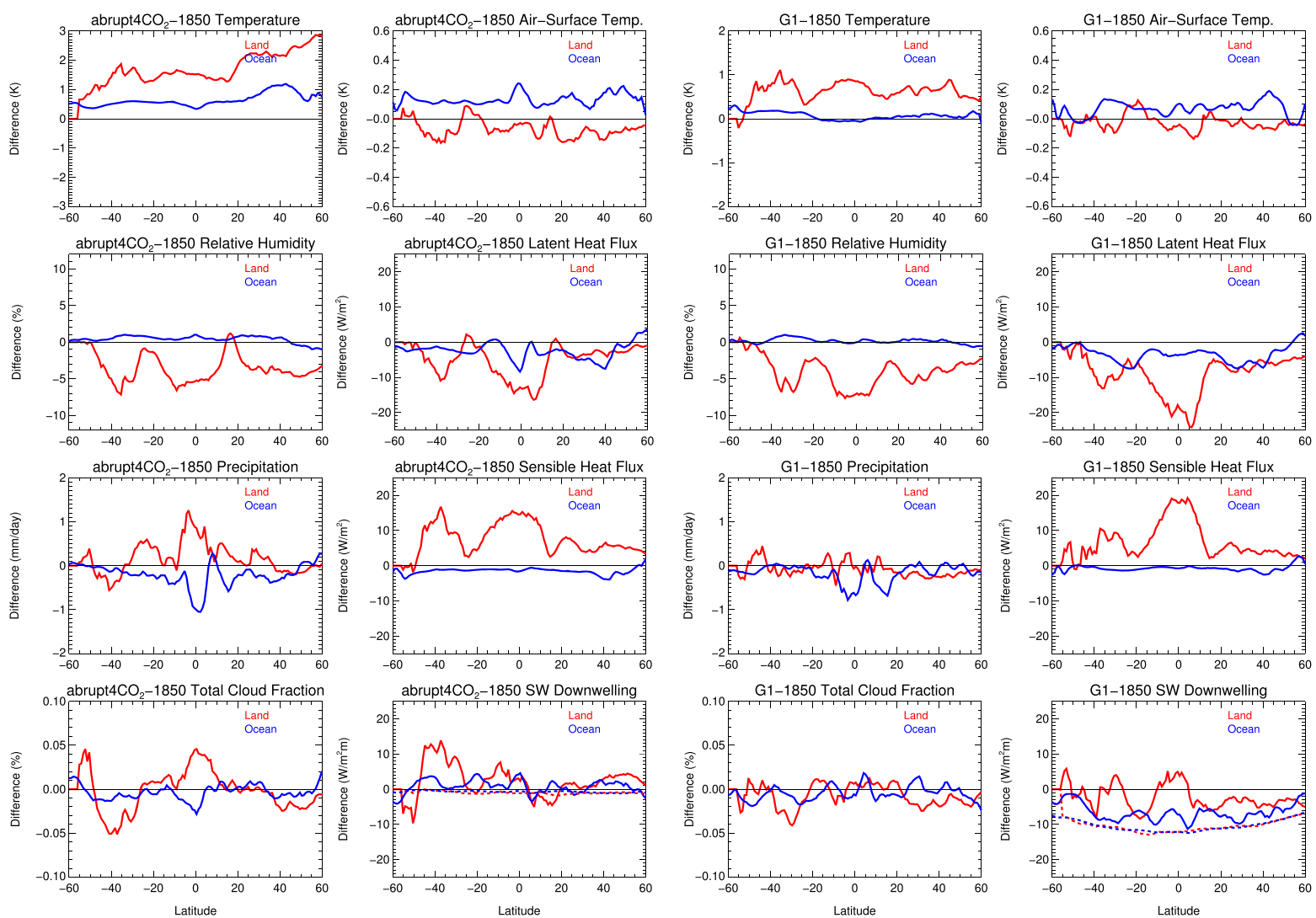

Figure A1. Annually averaged zonal absolute changes of CCSM model results for the first year of the simulation over land (red solid line) and over the ocean (blue solid line) between (left) $4 \times \mathrm{CO}_{2}$ and (right) G1 experiments with regard to 1850 conditions for the following variables: temperatures (first row, left); air-to-surface temperature difference (first row, right), relative humidity (second row, left), latent heat flux (second row, right), precipitation (third row, left), sensible heat flux (third row, right), cloud fraction (bottom row, left), and shortwave downwelling with clear sky, dashed, and full sky, solid (bottom row, right).

shortwave (SW) radiation is of opposite sign due to the global decrease in solar intensity in G1. Over land, LH and $\mathrm{RH}$ are strongly reduced at most latitudes with the largest absolute changes in LH occurring in the tropics (Figure A1, second row). Further, SH and net LW flux (not shown) over land increase to balance the reduction in $\mathrm{LH}$.

[60] Simulations omitting the response in stomatal conductance reveal the importance of this process (Figure A2). Changes in LH and RH over land are small relative to the GeoMIP simulations that include the influence of stomatal conductance (Figure A2, second row). Significant differences are also obvious for the other fields over land. For instance, if the stomatal response is turned off, warming over land is small under G1 conditions (Figure A2, first row), whereas it exceeds $0.5 \mathrm{~K}$ when the stomatal response is included (Figure A1, first row), consistent with earlier studies [e.g., Joshi et al., 2008; Cao et al., 2010]. On the other hand, no significant differences over ocean are evident.

[61] Therefore, these simulations suggest that the fast precipitation response over land is strongly influenced by stomatal conductance. A reduction of $\mathrm{LH}$ in both $4 \times \mathrm{CO}_{2}$ and G1 experiments is to a large part controlled by the abrupt reduction of the stomatal conductance of plants due to the increase of $\mathrm{CO}_{2}$, which in turn impacts temperature, precipitation, and clouds [Ban-Weiss et al., 2011; Fyfe et al., 2013; Cao et al., 2012]. For the $4 \times \mathrm{CO}_{2}$ experiment, clouds decrease over land in midlatitudes but increase markedly in the deep tropics (Figure A1). Increases in the deep tropics appear to be related to warming of the land surface and an overall strengthening of the hydrologic cycle in the $4 \times \mathrm{CO}_{2}$ experiment and a resultant increase in convective instability, rainfall, and large-scale convergence. For G1, changes in clouds are relatively weak throughout most of the tropics and coincide with an overall weakening of the hydrologic cycle, a reduction in LH flux compared to the $4 \times \mathrm{CO}_{2}$ experiment, which further interacts with the downwelling SW radiation. If the stomatal conductance is not adjusted to high $\mathrm{CO}_{2}$ concentrations, the initial increase in rainfall over land in the $4 \times \mathrm{CO}_{2}$ experiment (Figure A2, first column, third row) is actually smaller than with the adjustment (Figure A1, first column, third row) for the first year of the simulation, which coincides with less warming over land. These findings are in agreement with a more detailed investigation of the physiological effect of $\mathrm{CO}_{2}$ on climate [Cao et al., 2012], showing that the fast adjustment is occurring within days of the simulation. 

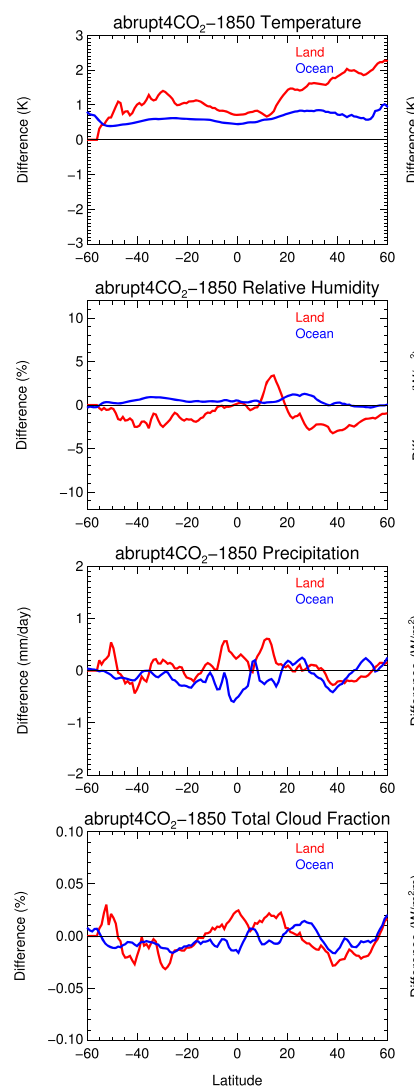
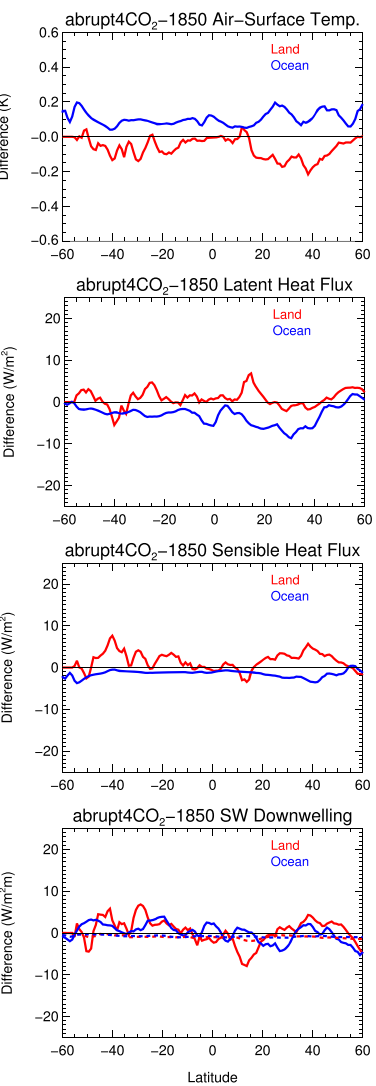
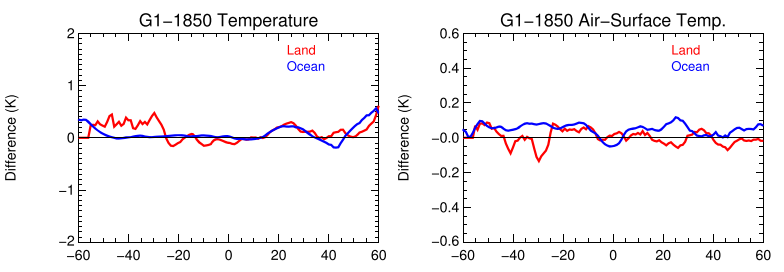

G1-1850 Relative Humidity
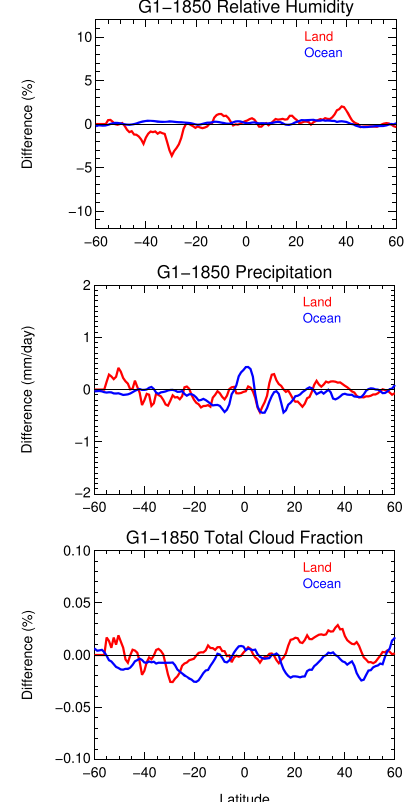
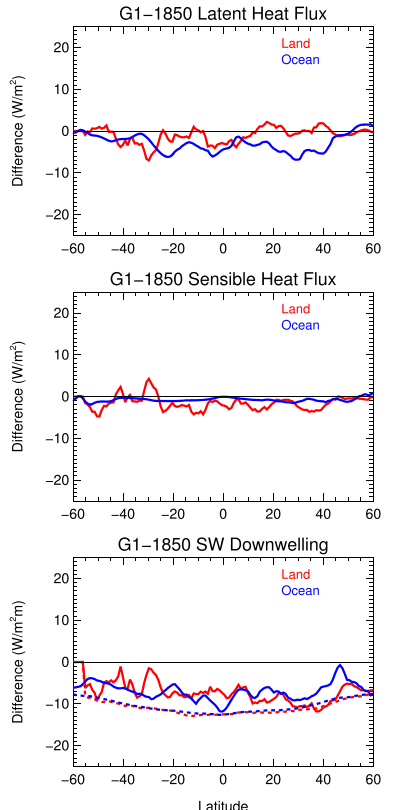

Figure A2. As Figure A1, however, the $4 \times \mathrm{CO}_{2}$ model experiment and $\mathrm{G} 1$ do not include any changes in stomatal conductance as a result of the abrupt increase in $\mathrm{CO}_{2}$ concentrations.

[62] Acknowledgments. We thank all participants of the Geoengineering Model Intercomparison Project and their model development teams, the CLIVAR/WCRP Working Group on Coupled Modeling for endorsing GeoMIP, and the scientists managing the Earth System Grid data nodes who have assisted with making GeoMIP output available. We further acknowledge the World Climate Research Programme's Working Group on Coupled Modelling, which is responsible for CMIP, and we thank the climate modeling groups for producing and making available their model output. For CMIP, the U.S. Department of Energy's Program for Climate Model Diagnosis and Intercomparison provides coordinating support and led development of software infrastructure in partnership with the Global Organization for Earth System Science Portals. We thank the TRMM Online Visualization and Analysis System (TOVAS) and the GPCC Global Precipitation Climatology Centre for providing the rainfall data set. The participation of J. Fasullo is supported by NASA Award NNG06GB91G. J. Haywood and A. Jones were supported by the joint DECC/Defra Met Office Hadley Centre Climate Programme (GA01101). K. Alterskjær, D. B. Karam, J. E. Kristjánsson, U. Niemeier, H. Schmidt, and M. Schulz received funding from the European Unions Seventh Framework Programme (FP7/2007-2013) under grant agreement 226567-IMPLICC. K. Alterskjær and J.E. Kristjánsson received support from the Norwegian Research Council's Programme for Supercomputing (NOTUR) through a grant of computing time. B. Kravitz is supported by the Fund for Innovative Climate and Energy Research. Simulations performed by B. Kravitz were supported by the NASA High-End Computing (HEC) Program through the NASA Center for Climate Simulation (NCCS) at Goddard Space Flight Center. Computer resources for P.J. Rasch, B. Singh, and J.-H. Yoon were provided by the National Energy Research Scientific Computing Center, which is supported by the Office of Science of the U.S. Department of Energy under Contract DE-AC02-05CH11231. J.-H. Yoon was further supported by the NERSC. D. Ji and J. Moore thank all members of the BNU-ESM model group, as well as the Center of Information and Network Technology at Beijing Normal University for assistance in publishing the GeoMIP data set. H. Muri was supported by the EU 7th Framework Programme grant agreement 306395, EuTRACE. A. Robock is supported by the U.S. National Science Foundation grant AGS-1157525. S. Watanabe was supported by SOUSEI Program, MEXT, Japan, and the Earth Simulator was used for the simulations of MIROC-ESM. Finally, we thank Gary Strand for CCSM4 output formatting and James Hurrell for supporting this study. The National Center for Atmospheric Research is funded by the National Science Foundation. We thank all reviewers and Govindasamy Bala for useful suggestions to the paper.

\section{References}

Adler, R., et al. (2003), The Version-2 Global Precipitation Climatology Project (GPCP) monthly precipitation analysis $(1979-$ present), $J$ Hydrometeorol., 4, 1147-1167.

Andrews, T., and P. M. Forster (2010), The transient response of globalmean precipitation to increasing carbon dioxide levels, Environ. Res. Lett., 5(2), 025,212, 1-6, doi:10.1088/1748-9326/5/2/025212.

Andrews, T., P. M. Forster, and J. M. Gregory (2009), A surface energy perspective on climate change, J. Clim., 22(10), 2557-2570, doi:10.1175/2008JCLI2759.1.

Angel, R. (2006), Feasibility of cooling the Earth with a cloud of small spacecraft near the inner Lagrange point (L1), Proc. Natl. Acad. Sci. U.S.A., 103(46), 17,184-17,189.

Arakawa, A., and W. H. Schubert (1974), Interactions of cumulus cloud ensemble with the large-scale environment, Part I, J. Atmos. Sci., 31, 674-701

Bala, G., P. B. Duffy, and K. E. Taylor (2008), Impact of geoengineering schemes on the global hydrological cycle, Proc. Natl. Acad. Sci. U.S.A., 105(22), 7664-7669, doi:10.1073/pnas.0711648105.

Bala, G., K. Caldeira, R. Nemani, L. Cao, G. Ban-Weiss, and H.-J. Shin (2010), Albedo enhancement of marine clouds to counteract global warming: Impacts on the hydrological cycle, Clim. Dyn., 37(5-6), 915-931, doi:10.1007/s00382-010-0868-1.

Ban-Weiss, G. A., G. Bala, L. Cao, J. Pongratz, and K. Caldeira (2011), Climate forcing and response to idealized changes in surface latent and sensible heat, Environ. Res. Lett., 6(3), 034,032, 1-8, doi:10.1088/17489326/6/3/034032. 
Bluth, G. J. S., S. D. Doiron, C. C. Schnetzler, A. J. Krueger, and L. S. Walter (1992), Global tracking of the $\mathrm{SO}_{2}$ clouds from the June, 1991 Mount Pinatubo eruptions, Geophys. Res. Lett., 19(2), 151-154.

Boos, W. R., and Z. Kuang (2010), Dominant control of the South Asian monsoon by orographic insulation versus plateau heating, Nature, 463(7278), 218-222, doi:10.1038/nature08707.

Boucher, O., P. R. Halloran, E. J. Burke, M. Doutriaux-Boucher, C. D. Jones, J. Lowe, M. A. Ringer, E. Robertson, and P. Wu (2012), Reversibility in an Earth System model in response to $\mathrm{CO}_{2}$ concentration changes, Environ. Res. Lett., 7(2), 024,013, 1-9, doi:10.1088/17489326/7/2/024013.

Canty, T., N. R. Mascioli, M. D. Smarte, and R. J. Salawitch (2013), An empirical model of global climate - Part 1: A critical evaluation of volcanic cooling, Atmos. Chem. Phys., 13(8), 3997-4031, doi:10.5194/acp13-3997-2013.

Cao, L., G. Bala, K. Caldeira, R. Nemani, and G. Ban-Weiss (2010), Importance of carbon dioxide physiological forcing to future climate change, Proc. Natl. Acad. Sci. U.S.A., 107(21), 9513-9518, doi:10.1073/pnas.0913000107.

Cao, L., G. Bala, and K. Caldeira (2012), Climate response to changes in atmospheric carbon dioxide and solar irradiance on the time scale of days to weeks, Environ. Res. Lett., 7(3), 034,015, 1-7, doi:10.1088/17489326/7/3/034015

Chou, C., C.-A. Chen, P.-H. Tan, and K. T. Chen (2012), Mechanisms for global warming impacts on precipitation frequency and intensity, $J$. Clim., 25(9), 3291-3306, doi:10.1175/JCLI-D-11-00239.1.

Crutzen, P. J. (2006), Albedo enhancements by stratospheric sulfur injections: A contribution to resolve a policy dilemma? An Editorial Essay, Clim. Change, 77, 211-219.

Del Genio, A. D., and M.-S. Yao (1993), Efficient cumulus parameterization for long-term climate studies: The GISS scheme, in The Representation of Cumulus Convection in Numerical Models, Meteor. Monogr., Am. Meteorol. Soc., 46, 181-184.

Doutriaux-Boucher, M., M. J. Webb, J. M. Gregory, and O. Boucher (2009), Carbon dioxide induced stomatal closure increases radiative forcing via a rapid reduction in low cloud, Geophys. Res. Lett., 36, L02703, doi:10.1029/2008GL036273.

Durack, P. J., S. E. Wijffels, and R. J. Matear (2012), Ocean salinities reveal strong global water cycle intensification during 1950 to 2000, Science, 336(6080), 455-458, doi:10.1126/science.1212222.

Emanuel, K. (1991), A scheme for representing cumulus convection in large-scale models, J. Atmos. Sci., 48, 2313-2335.

Emori, S., T. Nozawa, A. Numaguti, and I. Uno (2001), Importance of cumulus parameterization for precipitation simulation over East Asia in June, J. Meteorol. Soc. Jpn., 79(4), 939-947, doi:10.2151/jmsj. 79.939.

Fasullo, J. (2012), A mechanism for land-ocean contrasts in global monsoon trends in a warming climate, Clim. Dyn., 39(5), 1137-1147, doi:10.1007/s00382-011-1270-3.

Fasullo, J. T. (2010), Robust land-ocean contrasts in energy and water cycle feedbacks, J. Clim., 23(17), 4677-4693, doi:10.1175/2010JCLI3451.1.

Fasullo, J. T., and K. E. Trenberth (2012), A less cloudy future: The role of subtropical subsidence in climate sensitivity, Science, 338(6108), 792-794, doi:10.1126/science. 1227465.

Fyfe, J. C., J. N. S. Cole, V. K. Arora, and J. F. Scinocca (2013), Biogeochemical carbon coupling influences global precipitation in geoengineering experiments, Geophys. Res. Lett., 40, 651-655, doi:10.1002/grl.50166.

Govindasamy, B., and K. Caldeira (2000), Geoengineering Earth's radiation balance to mitigate $\mathrm{CO}_{2}$-induced climate change, Geophys. Res. Lett. 27(14), 2141-2144.

Govindasamy, B., K. Caldeira, and P. Duffy (2003), Geoengineering Earth's radiation balance to mitigate climate change from a quadrupling of $\mathrm{CO}_{2}$, Global Planet. Change, 37(1-2), 157-168, doi:10.1016/S09218181(02)00195-9.

Gregory, D., and P. R. Rowntree (1990), A mass flux convection scheme with representation of cloud ensemble characteristics and stabilitydependent closure, Mon. Weather Rev., 118, 1483-1506.

Gregory, J. M., W. J. Ingram, M. A. Palmer, G. S. Jones, P. A. Stott, R. B. Thorpe, J. A. Lowe, T. C. Johns, and K. D. WIlliams (2004), A new method for diagnosing radiative forcing and climate sensitivity, Geophys. Res. Lett., 31, L03205, doi:10.1029/2003GL018747.

Hansen, G., T. Svenøe, M. P. Chipperfield, A. Dahlback, and U.-P. Hoppe (1997), Evidence of substantial ozone depletion in winter 1995/96 over Northern Norway, Geophys. Res. Lett., 24, 799-802.

Haywood, J. M., A. Jones, N. Bellouin, and D. Stephenson (2013), Asymmetric forcing from stratospheric aerosols impacts Sahelian rainfall, Nat. Clim. Change, 3, 660-665, doi:10.1038/nclimate1857.

Heckendorn, P., D. Weisenstein, S. Fueglistaler, B. P. Luo, E. Rozanov, M. Schraner, L. W. Thomason, and T. Peter (2009), The impact of geoengi- neering aerosols on stratospheric temperature and ozone, Environ. Res. Lett., 4, 045,108, 1-12, doi:10.1088/1748-9326/4/4/045108.

Hegerl, G. C., and S. Solomon (2010), Climate change. Risks of climate engineering, Science, 325(5943), 955-956, doi:10.1126/science. 1178530 .

Held, I. M., and B. Soden (2006), Robust responses of the hydrological cycle to global warming, J. Clim., 19, 5686-5699.

Hsu, P.-C., T. Li, H. Murakami, and A. Kitoh (2013), Future change of the global monsoon revealed from 19 CMIP5 models, J. Geophys. Res. Atmos., 118, 1247-1260, doi:10.1002/jgrd.50145.

Huffman, G. J., R. F. Adler, D. T. Bolvin, and G. Gu (2009), Improving the global precipitation record: GPCP version 2.1, Geophys. Res. Lett., 36 L17808, doi:10.1029/2009GL040000.

Irvine, P. J., A. Ridgwell, and D. J. Lunt (2010), Assessing the regional disparities in geoengineering impacts, Geophys. Res. Lett., 37, L18702, doi:10.1029/2010GL044447.

Jones, A., J. Haywood, O. Boucher, B. Kravitz, and A. Robock (2010), Geoengineering by stratospheric $\mathrm{SO}_{2}$ injection: Results from the Met Office HadGEM2 climate model and comparison with the Goddard Institute for Space Studies ModelE, Atmos. Chem. Phys., 10(13), 5999-6006, doi:10.5194/acp-10-5999-2010.

Joshi, M. M., J. M. Gregory, M. J. Webb, D. M. H. Sexton, and T. C. Johns (2008), Mechanisms for the land/sea warming contrast exhibited by simulations of climate change, Clim. Dyn., 30, 455-465.

Kravitz, B., and A. Robock (2011), Climate effects of high-latitude volcanic eruptions: Role of the time of year, J. Geophys. Res., 116, D01105, doi:10.1029/2010JD014448.

Kravitz, B., A. Robock, O. Boucher, H. Schmidt, K. E. Taylor, G. Stenchikov, and M. Schulz (2011), The Geoengineering Model Intercomparison Project (GeoMIP), Atmos. Sci. Lett., 12(2), 162-167, doi:10.1002/asl.316.

Kravitz, B., et al. (2013), Climate model response from the Geoengineering Model Intercomparison Project (GeoMIP), J. Geophys. Res. Atmos., 118, 8320-8332, doi:10.1002/jgrd.50646.

Lambert, F. H., M. J. Webb, and M. M. Joshi (2011), The relationship between land-ocean surface temperature contrast and radiative forcing, J. Clim., 24(13), 3239-3256, doi:10.1175/2011JCLI3893.1.

Launder, B., and J. Thompson (Eds.) (2009), Geo-Engineering Climate Change: Environmental Necessity or Pandora's Box? Cambridge Univ. Press

Lee, J.-Y., and B. Wang (2012), Future change of global monsoon in the CMIP5, Clim. Dyn., 41,573-41,587, doi:10.1007/s00382-012-1564-0.

Lin, J.-L. (2007), The double-ITCZ problem in IPCC AR4 coupled GCMs: Ocean-atmosphere feedback analysis, J. Clim., 20, 4497-4525.

Liu, X., et al. (2012), Toward a minimal representation of aerosols in climate models: Description and evaluation in the Community Atmosphere Model CAM5, Geosci. Model Dev., 5(3), 709-739, doi:10.5194/gmd-5709-2012.

Lunt, D. J., A. Ridgwell, P. J. Valdes, and A. Seale (2008), "Sunshade World": A fully coupled GCM evaluation of the climatic impacts of geoengineering, Geophys. Res. Lett., 35, L12710, doi:10.1029/ 2008 GL033674.

McCormick, M. P., L. W. Thomason, and C. R. Trepte (1995), Atmospheric effects of the Mt. Pinatubo eruption, Nature, 373, 399-404.

Neale, R. B., J. H. Richter, and M. Jochum (2008), The impact of convection on ENSO: From a delayed oscillator to a series of events, J. Clim. 21(22), 5904-5924, doi:10.1175/2008JCLI2244.1.

Niemeier, U., H. Schmidt, and C. Timmreck (2010), The dependency of geoengineered sulfate aerosol on the emission strategy, Atmos. Sci. Lett., 12, 189-194, doi:10.1002/asl.304.

Nordeng, T. E. (1994), Extended versions of the convective parameterization scheme at ECMWF and their impact on the mean and transient activity of the model in the tropics, Tech. Memo., European Centre for Medium-Range Weather Forecasts.

O'Gorman, P. A. (2012), Sensitivity of tropical precipitation extremes to climate change, Nat. Geosci., 5(10), 697-700, doi:10.1038/ ngeo1568.

Park, S., and C. S. Bretherton (2009), The University of Washington shallow convection and moist turbulence schemes and their impact on climate simulations with the Community Atmosphere Model, J. Clim., 22(12), 3449-3469, doi:10.1175/2008JCLI2557.1.

Pongratz, J., D. B. Lobell, L. Cao, and K. Caldeira (2012), Crop yields in a geoengineered climate, Nat. Clim. Change, 2(2), 101-105, doi:10.1038/nclimate1373.

Rasch, P. J., S. Tilmes, R. P. Turco, A. Robock, L. Oman, C.-C. Chen, G. L. Stenchikov, and R. R. Garcia (2008), An overview of geoengineering of climate using stratospheric sulphate aerosols, Philos. Trans. R. Soc. London, Ser. A, 366(1882), 4007-4037, doi:10.1098/rsta.2008.0131.

Richter, J., and P. J. Rasch (2008), Effects of convective momentum transport on the atmospheric circulation in the Community 
Atmosphere Model, version 3, J. Clim., 21, 1487-1499, doi:10.1175 2007JCLI1789.1.

Robock, A., L. Oman, and G. L. Stenchikov (2008), Regional climate responses to geoengineering with tropical and Arctic $\mathrm{SO}_{2}$ injections, $J$. Geophys. Res., 113, D16101, doi:10.1029/2008JD010050.

Scheff, J., and D. M. W. Frierson (2012), Robust future precipitation declines in CMIP5 largely reflect the poleward expansion of model subtropical dry zones, Geophys. Res. Lett., 39, L18704, doi:10.1029/2012GL052910.

Schmidt, H., et al. (2012), Solar irradiance reduction to counteract radiative forcing from a quadrupling of $\mathrm{CO}_{2}$ : Climate responses simulated by four earth system models, Earth Syst. Dyn., 3(1), 63-78, doi:10.5194/esd-363-2012.

Seager, R., N. Naik, and G. A. Vecchi (2010), Thermodynamic and dynamic mechanisms for large-scale changes in the hydrological cycle in response to global warming, J. Clim., 23(17), 4651-4668, doi:10.1175/2010JCLI3655.1.

Seth, A., S. A. Rauscher, M. Rojas, A. Giannini, and S. J. Camargo (2010), Enhanced spring convective barrier for monsoons in a warmer world?, Clim. Change, 104(2), 403-414, doi:10.1007/s10584-010-9973-8.

Soden, B. J., R. T. Wetherald, G. L. Stenchikov, and A. Robock (2002), Global cooling after the eruption of Mount Pinatubo: A test of climate feedback by water vapor, Science, 296(5568), 727-730, doi:10.1126/science.296.5568.727.

Solomon, S., D. Qin, M. Manning, M. Marquis, K. Averyt, M. M. B. Tignor, H. L. Miller, and Z. Chen (Eds.) (2007), Climate Change 2007: The Physical Science Basis. Contribution of Working Group I to the Fourth Assessment Report of the Intergovernmental Panel on Climate Change, 996 pp., Cambridge Univ. Press, Cambridge, U. K. and New York.

Sperber, K. R., H. Annamalai, I.-S. Kang, A. Kitoh, A. Moise, A. Turner, B. Wang, and T. Zhou (2012), The Asian summer monsoon: An intercomparison of CMIP5 vs. CMIP3 simulations of the late 20th century, Clim. Dyn., (2), doi:10.1007/s00382-012-1607-6.

Stenchikov, G., A. Robock, V. Ramaswamy, M. D. Schwarzkopf, K. Hamilton, and S. Ramachandran (2002), Arctic Oscillation response to the 1991 Mount Pinatubo eruption: Effects of volcanic aerosols and ozone depletion, J. Geophys. Res., 107(D24), 4803, doi:10.1029/2002JD002090.

Stephens, G. L., J. Li, M. Wild, C. A. Clayson, N. Loeb, S. Kato, T. L'Ecuyer, P. W. Stackhouse, M. Lebsock, and T. Andrews (2012), An update on Earth's energy balance in light of the latest global observations, Nat. Geosci., 5(10), 691-696, doi:10.1038/ngeo1580.

Sutton, R. T., B. Dong, and J. M. Gregory (2007), Land/sea warming ratio in response to climate change: IPCC AR4 model results and comparison with observations, Geophys. Res. Lett., 34, L02701, doi:10.1029/2006GL028164.

Taylor, K. E., R. J. Stouffer, and G. A. Meehl (2012), An overview of CMIP5 and the experiment design, Bull. Am. Meteorol. Soc., 93(4), 485-498, doi:10.1175/BAMS-D-11-00094.1.

Tiedtke, M. (1989), A comprehensive mass flux scheme for cumulus parameterization in large-scale models, Mon. Weather Rev., 117, 1779-1800.

Tilmes, S., R. Müller, and R. Salawitch (2008), The sensitivity of polar ozone depletion to proposed geoengineering schemes, Science, 320 (5880), 1201-1204, doi:10.1126/science.1153966.

Tilmes, S., R. R. Garcia, D. E. Kinnison, A. Gettelman, and P. J. Rasch (2009), Impact of geoengineered aerosols on the troposphere and stratosphere, J. Geophys. Res., 114, D12305, doi:10.1029/2008JD011420.

Trenberth, K. E. (1999), Conceptual framework for changes of extremes of the hydrological cycle with climate change, Clim. Change, 42, 327-339.

Trenberth, K. E., and A. Dai (2007), Effects of Mount Pinatubo volcanic eruption on the hydrological cycle as an analog of geoengineering, Geophys. Res. Lett., 34, L15702, doi:10.1029/2007GL030524.

Trenberth, K. E., A. Dai, R. M. Rasmussen, and D. B. Parsons (2003), The changing character of precipitation, Bull. Am. Meteorol. Soc., 84, 1205-1217

von Salzen, K., J. F. Scinocca, N. A. McFarlane, J. Li, J. N. S. Cole, D. Plummer, M. C. Reader, X. Ma, M. Lazare, and L. Solheim (2013), The Canadian Fourth Generation Atmospheric Global Climate Model (CanAM4). Part I: Physical processes, Atmos. Ocean, 51, $104-125$.

Wang, B., and Q. Ding (2006), Changes in global monsoon precipitation over the past 56 years, Geophys. Res. Lett., 33(6), L06711, doi:10.1029/2005GL025347.

Wigley, T. M. (2006), A combined mitigation/geoengineering approach to climate stabilization, Science, 314, 452-454.

Zhang, G. J., and N. A. McFarlane (1995), Sensitivity of climate simulations to the parameterization of cumulus convection in the Canadian Climate Centre General Circulation Model, Atmos. Ocean, 33(3), 407-446.

Zhang, G. J., and M. Mu (2005), Effects of modifications to the ZhangMcFarlane convection parameterization on the simulation of the tropical precipitation in the National Center for Atmospheric Research Community Climate Model, version 3, J. Geophys. Res., 110, D09109, doi:10.1029/2004JD005617.

Zheng, Y., J.-L. Lin, and T. Shinoda (2012), The equatorial Pacific cold tongue simulated by IPCC AR4 coupled GCMs: Upper ocean heat budget and feedback analysis, J. Geophys. Res., 117, C05024, doi: $10.1029 / 2011 \mathrm{JC} 007746$. 